\title{
1 The structural evolution of the deep continental lithosphere
}

3 Authors: C.M. Cooper ${ }^{1 *}$, Meghan S. Miller², Louis Moresi ${ }^{3}$

4

$5 \quad{ }^{1}$ School of the Environment, Washington State University, PO Box 642812, Pullman

6 WA 99164-2812, USA, cmcooper@wsu.edu, "Corresponding author

$8{ }^{2}$ Department of Earth Sciences, University of Southern California, 3651 Trousdale

$9 \quad$ Pkwy, Los Angeles, CA 90089, USA

10

$11{ }^{3}$ School of Earth Sciences, University of Melbourne, McCoy Building, Parkville, VIC,

123010 Australia

13

14 Abstract

16 Continental lithosphere houses the oldest and thickest regions of the Earth's surface.

17 Locked within this deep and ancient rock record lies invaluable information about the

18 dynamics that has shaped and continue to shape the planet. Much of that history has

19 been dominated by the forces of plate tectonics which has repeatedly assembled super

20 continents together and torn them apart - the Wilson Cycle. While the younger regions

21 of continental lithosphere have been subject to deformation driven by plate tectonics, it

22 is less clear whether the ancient, stable cores formed and evolved from similar

23 processes. New insight into continental formation and evolution has come from 
24 remarkable views of deeper lithospheric structure using enhanced seismic imaging

25 techniques and the increase in large volumes of broadband data. Some of the most

26 compelling observations are that the continental lithosphere has a broad range in

27 thicknesses ( $<100$ to $>300 \mathrm{~km}$ ), has complex internal structure, and that the thickest

28 portion appears to be riddled with seismic discontinuities at depths between $\sim 80$ and

$29 \sim 130 \mathrm{~km}$. These internal structural features have been interpreted as remnants of

30 lithospheric formation during Earth's early history. If they are remnants, then we can

31 attempt to investigate the structure present in the deep lithosphere to piece together

32 information about early Earth dynamics much as is done closer to the surface. This

33 would help delineate between the differing models describing the dynamics of craton

34 formation, particularly whether they formed in the era of modern plate tectonics, a

35 transitional mobile-lid tectonic regime, or are the last fragments of an early, stagnant-lid

36 planet. Our review paper (re)introduces readers to the conceptual definitions of the

37 lithosphere and the complex nature of the upper boundary layer, then moves on to

38 discuss techniques and recent seismological observations of the continental

39 lithosphere. We then review geodynamic models and hypotheses for the formation of

40 the continental lithosphere through time and implications for the formation and

41 preservation of deep structure. These are contrasted with the dynamical picture of

42 modern day continental growth during lateral accretion of juvenile crust with reference to

43 examples from the Australian Tasmanides and the Alaskan accretionary margin. 


\section{Contents}

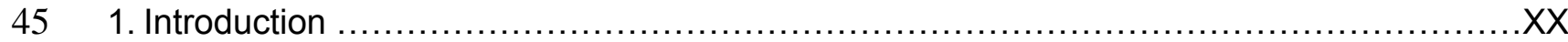

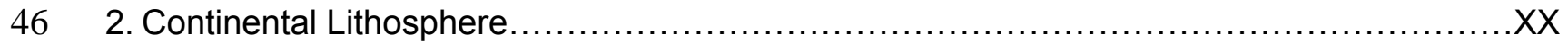

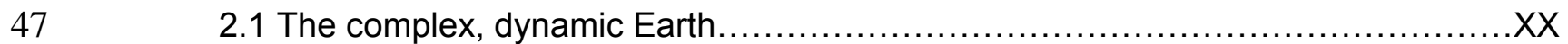

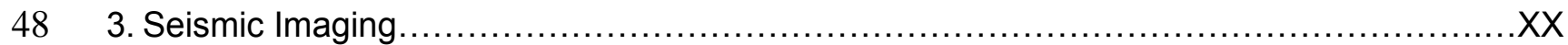

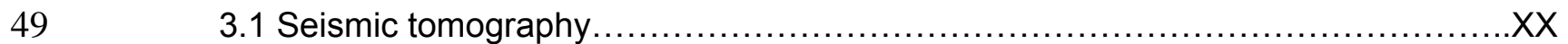

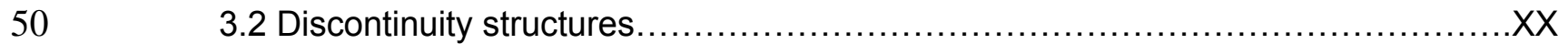

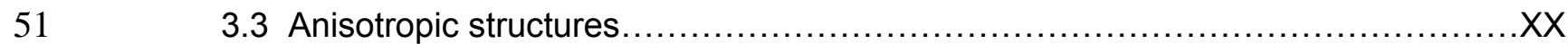

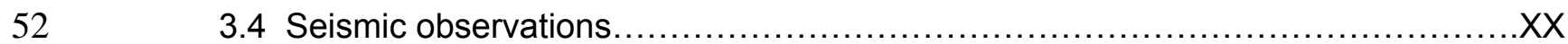

53 4. Dynamic Interpretation of Lithospheric Structure ...............................................

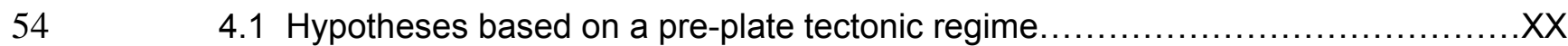

$55 \quad 4.2$ Hypotheses based on early development of plate tectonics ........................XX

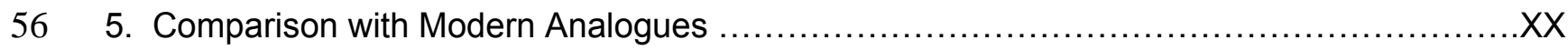

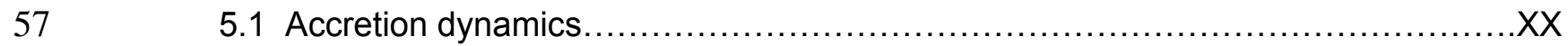

$58 \quad 5.2$ Examples from Australian Tasmanides and the Alaskan accretionary

$59 \quad \operatorname{margin} \ldots \ldots . . . . X X$

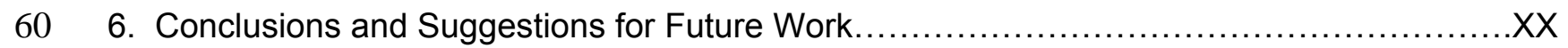

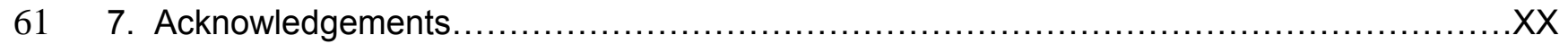

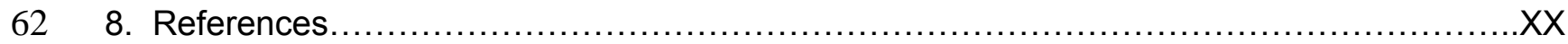

63 


\section{Introduction}

66 Despite serving as home to human civilization, the continental lithosphere is arguably

67 less well understood than the inaccessible oceanic lithosphere. This is because, while

68 the first-order features of the oceanic floor (heat flux, bathymetry and thickness) can be

69 directly attributed to the sea-floor age through plate-tectonics, that same theory fails to

70 provide an equivalent context for continents.

72 Due to research initiatives such as EarthScope and LITHOPROBE (Clowes et al.,

73 1999), along with greater computational power, there is now an unprecedented view of

74 the sub-crustal interior of continental and cratonic lithosphere. Most of this increased

75 coverage comes from a variety of seismic observations, which by their nature, provide

76 not an exact replication of continental lithosphere, but a glimpse of properties that

77 influence seismic parameters. As such, interpreting this expanded data requires not

78 only a critical analysis as to what would cause variations in seismic properties, but also

79 what geodynamic processes could produce the conditions required to produce an

80 anomaly.

81

82 What does this new glimpse into the interior of continents tell us about past conditions

83 and the history of deformation? How do we connect the new observations to other data

84 sets? And more broadly, can we turn this internal gaze into a larger view of the process

85 of building continents?

86

87 


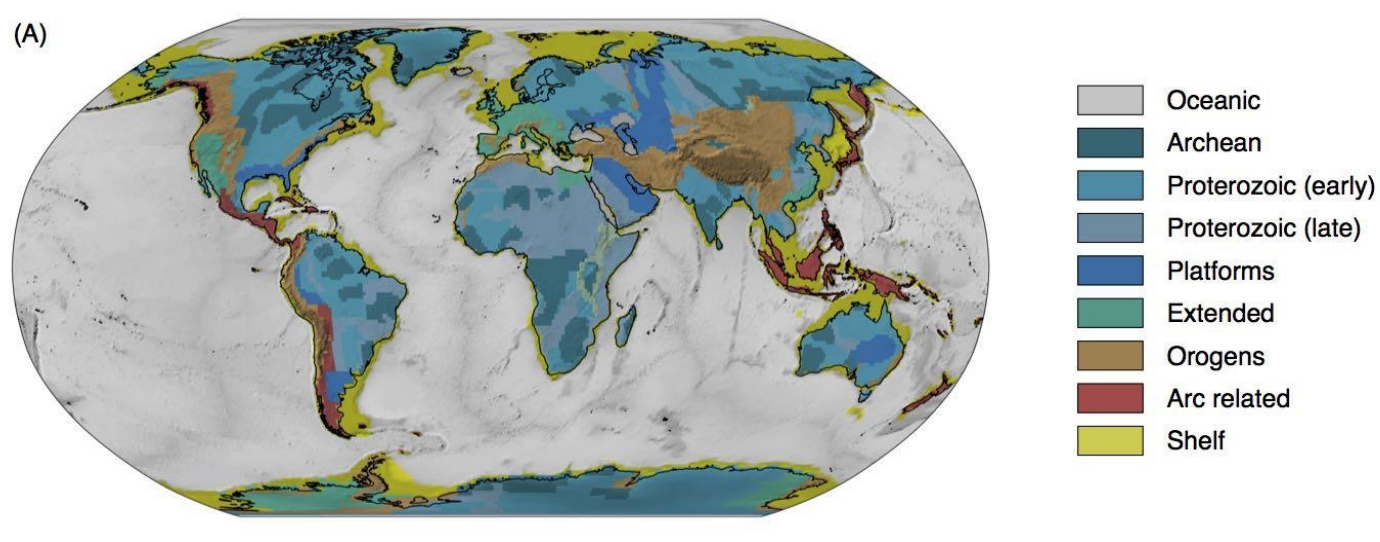

Laske et al, 2012

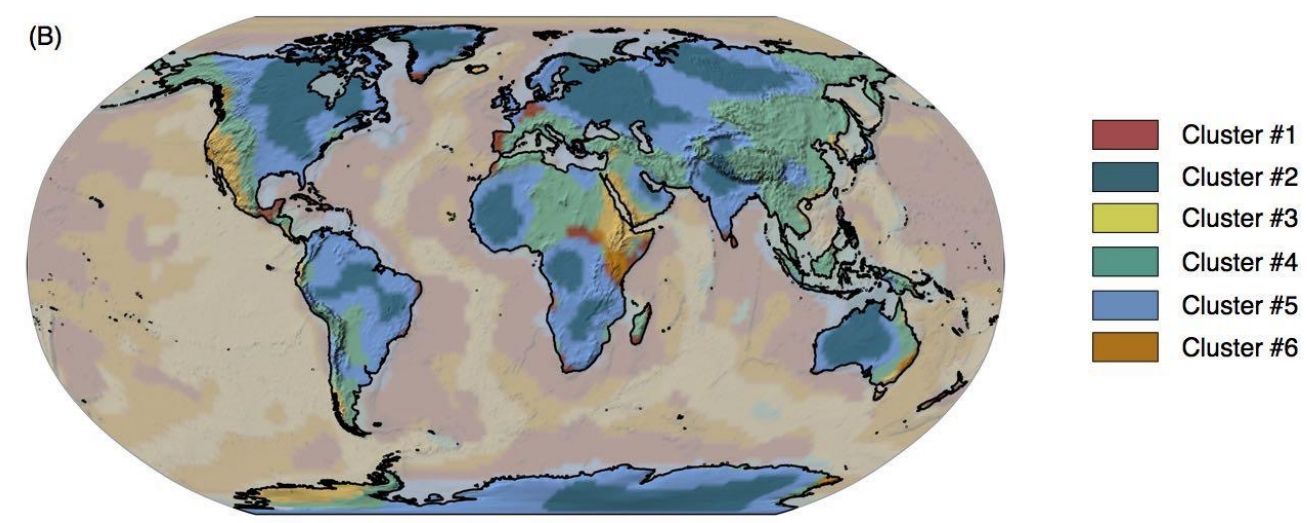

Lekic \& Ramanovicz, 2011

92 Figure 1. Two examples of global tectonic regionalization overlain on a shaded relief map from the ETOPO1 (Eakins

93 \& Amante, 2009). (A) the Crust 1.0 model (Laske et al., n.d.) based on 'shallow' geophysical observations and

94 geological provinces where we have amalgamated the 36 distinct crustal types globally into 9 related types for the

95 continents as described in the legend. (B) is the regionalization of (Lekic \& Romanowicz, 2011) clustering analysis of

96 global seismic tomography into six "similar" styles of lithosphere ("Clusters \#1-6") with no a priori constraints from

97 near-surface geology. In this model there is no distinction between continental and oceanic regions so we have

98 applied a translucent mask to emphasize the distribution of the clusters within the continents. The numbering is 
arbitrary and matches that chosen by the authors of the study, and we have chosen a color scheme which

emphasizes the similarity of old, stable regions in each map.

101

102 Global perspectives of the Earth's lithosphere highlight commonalities and differences

103 that can help guide our interpretations of the controls on lithospheric structure and

104 evolution. Figure 1 shows two different global decompositions of the lithosphere that

105 illustrate the first order domains using $(A)$ the top-down analysis of Crust1.0 from all

106 relevant geological and geophysical constraints (Laske et al., n.d.), together with (B) an

107 alternate regionalization based only on clustering similarities in the top $350 \mathrm{~km}$ of a

108 global, upper-mantle, seismic tomography model (Lekic \& Romanowicz, 2011). Despite

109 having been derived from very different means, some striking similarities exist that

110 serve to highlight the vertical coherence of the lithospheric structure at this broad scale.

111 For example, the cratons and the stable regions are picked out in both (darker blues),

112 and the actively deforming orogens are largely identified with a single cluster (\#4, shown

113 in green). It is also not entirely unexpected that there is some similarity between the

114 oceanic lithosphere and the regions of extension and rifting that is observed in the

115 cluster analysis. The deep-seated clustering approach is least helpful in regions where

116 the oceanic lithosphere is subducting beneath or close to the margin of the continent

117 where the deep lithosphere is unrelated to the shallower crust and lithosphere. These

118 clustering analyses suggest that, at a regional scale, deep and shallow lithospheric

119 evolution are linked and deep structure can be related to the long term evolution and

120 history of continental lithosphere. 
122 This is less obvious when looking at a similar global view of continental crust (Figure

123 2A). The global map of continental crustal thickness, using the litho1.0 data of

124 Pasyanos et al. (2014), is dominated by regions thickened by active orogenesis and

125 broadly corresponds to relief as would be expected for long-wavelength topography

126 supported by Airy isostasy. Crustal thickness appears to be less sensitive to past

127 events (outlined in Figure 2A). However, perhaps more interesting is the dichotomy

128 apparent in the relative thickness of crust to that of the lithosphere overall (Figure 2B)

129 which clearly delineates the stable continental interior from the tectonically mobile

130 regions (cf. clusters 3 and 4 of the Lekic \& Romanowicz (2011) analysis). This could be

131 indicating that, at least on the global scale, while the thickness of continental crust may

132 not serve as an indicator of time or preserve deep time events, variations in subcrustal

133 continental lithospheric thickness (and corresponding lithospheric structure) may be

134 potentially providing information about the deep history of deformation in the Earth.

135 Certainly, this is connected, in part, to the preferential preservation of thick, cratonic

136 lithosphere, but it could also be a hint that these regions could be informative in our

137 attempts in interpreting the dynamic settings of the Earth's past. 

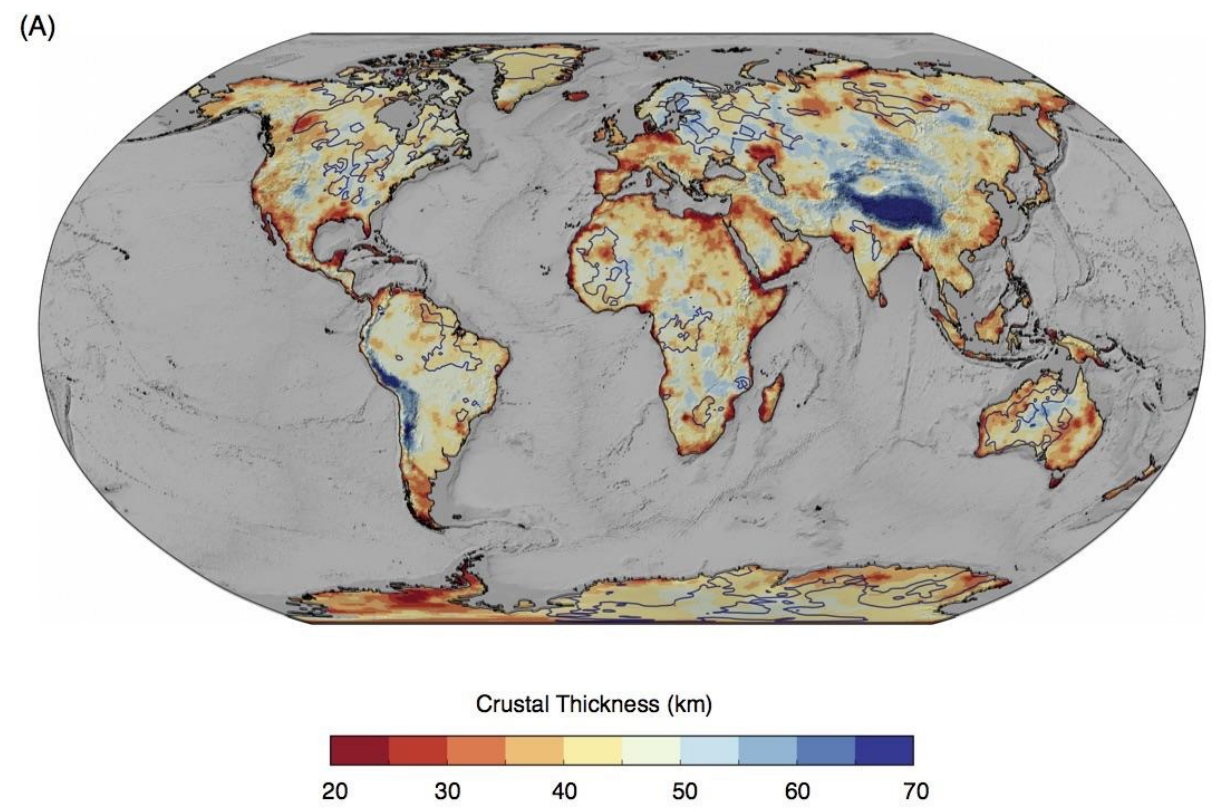

(B)
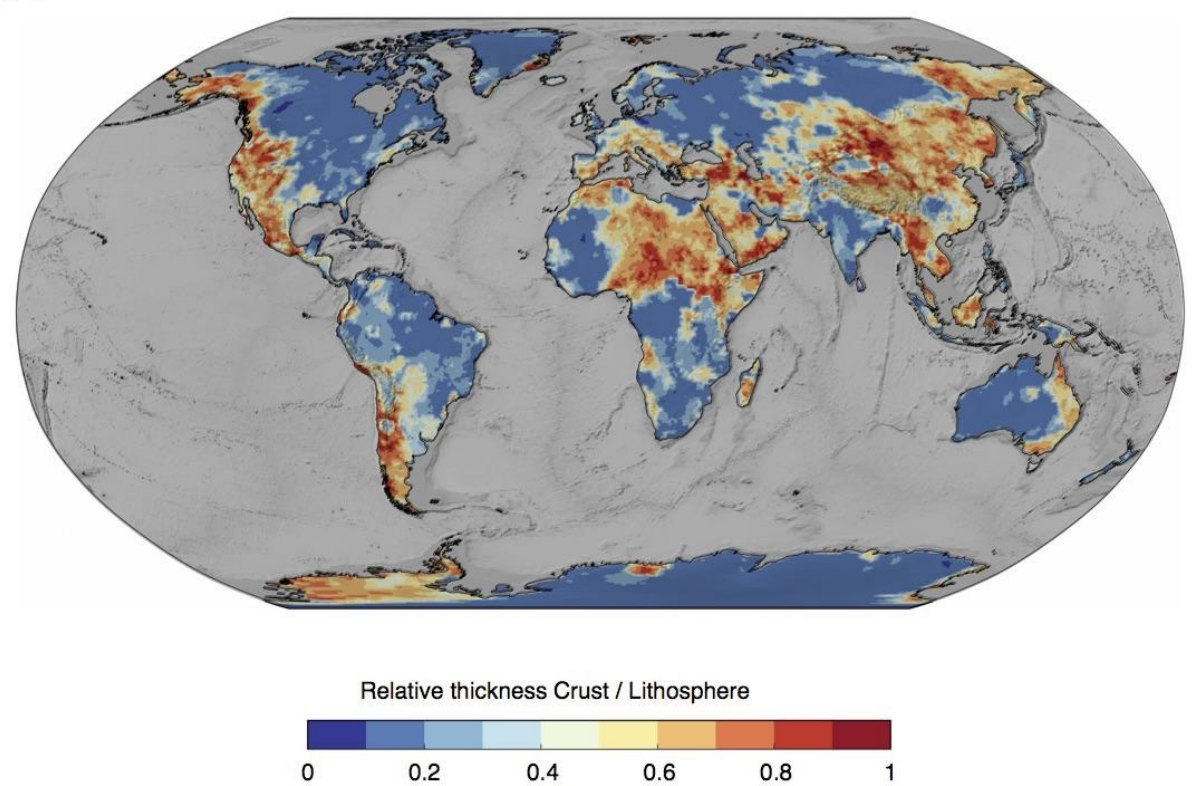

139 Figure 2. The thickness of the continental crust (A) and the relative thickness of the continental crust to total

140 lithospheric thickness (B) both derived from the layer thickness maps of litho1.0 (Pasyanos et al., 2014). In A, we 141 have outlined those regions where the depth to the lithosphere-asthenosphere boundary is greater than $250 \mathrm{~km}$. 
1431.1 The complex, dynamic Earth

145 As Earth scientists, we often call upon the tenet - "the present is the key to the past"

146 (Lyell, 1837) - to build analogies between geological observations across large spans of

147 time, appealing to a commonality in the underlying processes. This uniformitarian

148 approach has proven to be useful at explaining how the slow, but persistent nature of

149 change shapes the surface (and interior) of Earth. However, there is an important

150 caveat to the uniformitarian approach that applies to complex dynamical systems (the

151 Earth is certainly included in this category): while the driving processes may not change,

152 and the forcings may evolve gradually, the dynamic system does not necessarily evolve

153 smoothly and may instead jump through one or more catastrophic transitions between

154 distinctive regimes of behavior (e.g. Sanns, 2012).

156 We expect the early Earth to have higher overall heat production with a less evolved

157 mantle and less differentiated crust, for example, but, even if we assume the same

158 physical/chemical systems were operating under early-Earth conditions, should we

159 expect to see modern plate tectonics as an outcome (e.g. Dewey, 2007)? If the Earth

160 undergoes transitions in tectonic style, are the cratonic regions "survivors" from the

161 previous regime, or are they a by-product of the transition?

162

163 This shapes the broad context within which we can question the formation and

164 preservation of structure within the continental lithosphere. Is the old, stable lithosphere 
165 preserved because of some gradual stabilization process (e.g., Cooper et al., 2006) or

166 because the conditions of its formation produced regions with a stronger lithospheric

167 column (e.g., Poudjom Djomani et al., 2001)? If the latter, does the stable, cratonic

168 lithosphere represent anomalous regions from the time of formation or typical ones

169 which, by chance, avoided wholesale recycling or reworking (Lenardic et al., 2000)?

170 Are ancient lithospheres truly "forever" (O'Reilly et al., 2001) or susceptible to changing

171 mantle dynamics (Gao et al., 2004; Cooper et al., 2006; Abdelsalam et al., 2011; Guo et

172 al., 2016)? Can we bridge ancient and modern processes to build a continuous

173 conceptual model for continental evolution?

174

175 In the modern Earth, continental growth predominantly occurs through the lateral 176 accretion of juvenile crustal material along existing convergent margins driven by the 177 horizontal motion of the oceanic lithosphere (e.g., Cawood et al., 2009). The familiar 178 "conveyer belt" style of subduction is thought to have become active at some point 179 during the Archean (a time period spanning multiple billions of years), perhaps even 180 earlier, though the exact timing is still heavily debated. Shirey \& Richardson (2011) 181 argue that it occurred at $3.0 \mathrm{Ga}$ based on the appearance of eclogitic diamonds, which 182 are indicative of modern style subduction. Prior to $3.0 \mathrm{Ga}$, the inclusions within the 183 ancient diamonds point to a different compositional origin (one that samples the 184 average mantle rather than metamorphosed crust) (Shirey \& Richardson, 2011). 185 Recently, Tang et al. (2016) demonstrated a change in the bulk upper crust composition 186 from mafic to felsic also around 3.0 Ga further supporting the onset of plate tectonics 187 around this time. Though Shirey \& Richardson (2011) and Tang et al. (2016) argue that 
188 their evidence rules out an earlier start to plate tectonics, other studies push back this 189 date even earlier in Earth's history based on a myriad of other compositional, structural

190 and stratigraphic evidence (e.g., Betts et al., 2002; Chen et al., 2009; Polat \& Kerrich, 191 2006; Kerrich \& Polat, 2006; Furnes et al., 2007; Betts et al., 2011; Kusky et al., 2013;

192 Smart et al., 2016).

193

194 From a geodynamic point of view, the early viability of modern-style subduction is also

195 unclear. Due to higher mantle temperatures in the past, and the resulting thicker crust,

196 the oceanic lithosphere may have been too buoyant to participate in subduction

197 (Davies, 1992). This assumes a thicker oceanic crust (driven by increased melting due

198 to the higher mantle temperatures) as well as a more vigorous convection and

199 corresponding plate motion, both of which reduce the available negative buoyancy for

200 subduction. However, van Hunen \& van den Berg (2008) demonstrate that the rapid

201 transformation to dense eclogite of the thicker oceanic crust, due to higher mantle

202 temperatures, would have increased the negative buoyancy and allowed for subduction

203 during early Earth conditions albeit in a slightly modified manner: subduction may have

204 been episodic with slabs experiencing a significant amount of necking, thinning,

205 delamination or breaking apart. These discrepancies in the style and reduction in the

206 strength of subduction have been proposed to explain the lack of geochemical evidence

207 of modern style subduction prior to 3.0 Ga (van Hunen \& van den Berg, 2008). Some of

208 the other hallmark processes of subduction might still have been in operation though

209 occurring in sporadic bursts of activity (for more information about this debate, see van

210 Hunen \& Moyen, 2012). Davies (2006) has argued that an early and strong depletion of 
211 incompatible trace elements in the source region for mid-ocean-ridge melting would

212 produce an oceanic crust of comparable thickness to the modern Earth and,

213 correspondingly, a modern-style of subduction. However, the dynamics of subduction in

214 the early Earth and corresponding dynamics continental collision are likely to have been

215 different from their present form (e.g., Sizova et al., 2014).

216

217 The earliest continental material preserved in the geological record predates the

218 transition to plate tectonics (the oldest rock on the Earth was dated as $4.28 \mathrm{Ga}$; O'Neil

219 et al., 2008) and could serve as a witness to whichever mode of tectonic activity was

220 present. Modern-style plate tectonics occurs primarily through lateral translation of

221 continents across the surface of the Earthwith a characteristic signature of progressive

222 thickening from the margins inward. A pre-plate tectonic regime with weak or no

223 subduction is likely to have been more dominated by vertical motions. Such conceptual

224 models require that the entire surface of the Earth would have been a single, stagnant

225 plate with vigorous convection beneath. Within this premise, heat from the interior of

226 the early Earth would have been transferred through the lithosphere by conduction

227 (a.k.a. stagnant lid; Moresi \& Solomatov, 1995), by rapid and pervasive volcanic

228 eruptions (a.k.a. heat pipe; Moore \& Webb, 2013), or by episodic, intermittent,

229 catastrophic bursts of subduction (O'Neill et al., 2007; O’Neill \& Debaille, 2014). Each

230 of these conceptual models makes specific predictions for the expected tectonic

231 settings. Within stagnant lid and heat pipe regimes, deformation is driven primarily by

232 vertical motion (small scale drips and delamination, and vertical advection) with the

233 potential for regional, lateral motion as driven by gravitational collapse (Rey et al., 
234 2014). Episodic subduction suggests a more complex setting that captures both the

235 signatures of subduction, but also periods of stagnant lid convection.

237 As home to the oldest regions on the Earth (specifically the "cratons" which are defined

238 as the regions of the crust and lithospheric mantle that have not undergone deformation

239 in billions of years), the continental lithosphere should serve as a record for these past

240 conditions. In this paper, we review the current status of the research on the structure

241 and evolution of deep continental lithosphere with a focused gaze into what information

242 can be gained from the similarities and differences between older and younger

243 continental lithosphere. We begin with a discussion of the conceptual definitions used

244 to describe and characterize continental lithosphere. From there, we review recent

245 seismic observations of continental lithosphere and its complex internal structure. We

246 also briefly describe the seismological techniques used to make these observations.

247 We then move on to discuss a number of geodynamical models proposed for the

248 formation of continental lithosphere and the corresponding structures induced during

249 those processes. We follow that section with a comparison between the proposed

250 ancient processes and modern day analogues of continental accretion in Alaska and

251 Australia. Finally, we leave readers with potentially more questions that we initially

252 posed as well suggestions for future work.

\section{2. Continental Lithosphere}

254 The term lithosphere, while in use since 1914 (Barrell, 1914), remains an imprecise

255 concept with different disciplines defining the "layer of strength" in a variety of ways.

256 This is, in part, because it is unclear as to what is the primary control on the strength of 
257 Earth materials (e.g., temperature, composition, pressure) and also because the

258 timescale of loading and response plays an important role in interpreting strength (e.g.,

259 Watts et al., 2013). One approach is to treat the lithosphere as the thermal boundary

260 layer or the region encompassing the greatest temperature gradient near the surface of

261 the Earth. In this construct, the base of the lithosphere is defined as the depth at which

262 the temperature depth profile transitions from the steep gradient near the surface to

263 align with the mantle adiabat. The strength is then due primarily to temperature as the

264 mantle's viscosity is temperature dependent and below the lithosphere, the temperature

265 is sufficiently high to consider the material "weak" and subject to viscous, convective

266 deformation (for a full discussion see Eaton et al., 2009). To map out the base of the

267 lithosphere in this manner requires an approach that is sensitive to temperature within

268 the Earth's interior. One approach is to use surface heat flux measurements. The

269 surface heat flux is proportional to the near surface temperature gradient (i.e., Fourier's

270 law of heat conduction). If, then, the amount of heat production from the crust and

271 mantle is known, a regional geotherm (steady state temperature with depth profile) can

272 be derived using surface heat flux measurements (Figure 3).

273 

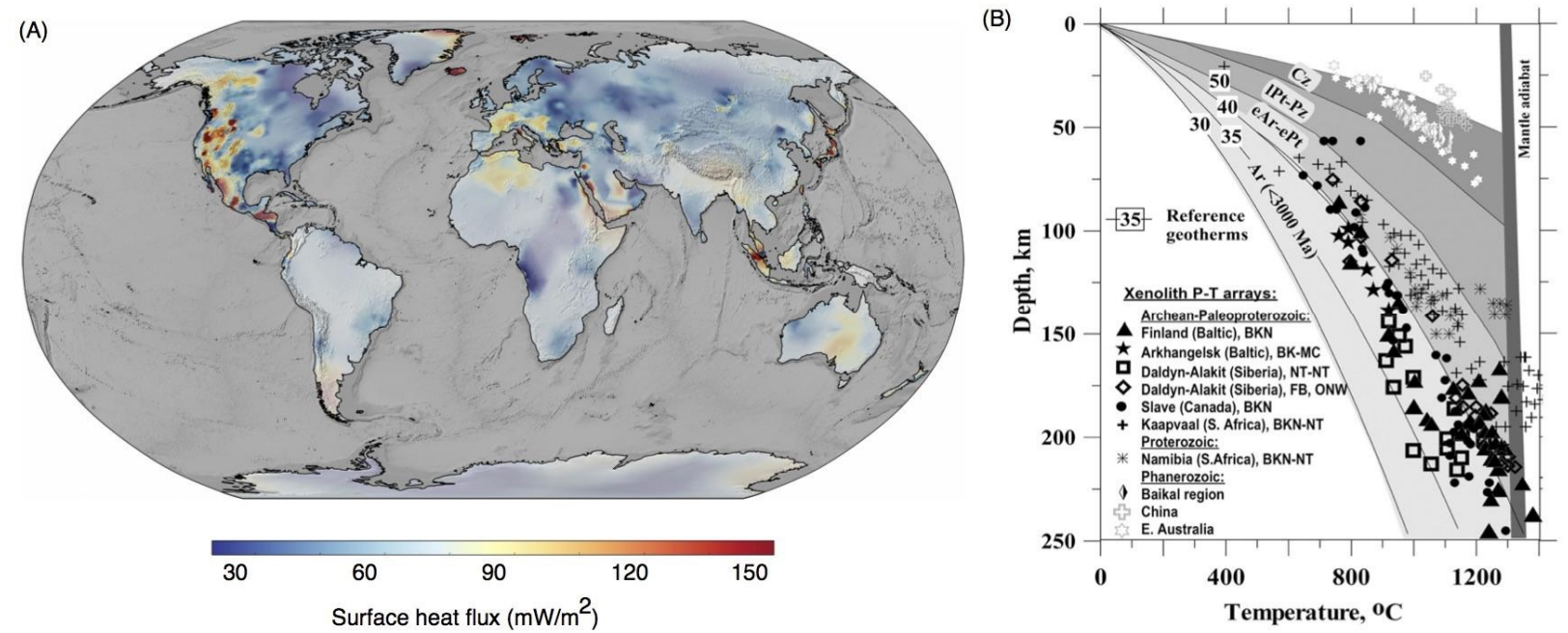

Figure 3. (A) Global surface heat flow measurements (International Heat Flow Commission) plotted by binning the point-measurement datasets to an adaptively-refined triangulation with a minimum resolution of $50 \mathrm{~km}$. Color saturation represents the resolution of the triangulation which washes out progressively such that the coarsest resolution is shown with only 5\% saturation. (B) Lithospheric geotherms for continental regions (Artemieva, 2009).

This approach depends on reliable surface heat flux measurements as well as

281 knowledge of the composition of the crust and upper mantle (in particular, the amount of

282 heat producing elements, which control the "curve" in the geotherm - for example, the

283 geotherm is much steeper at shallow depths when there is a high concentration of heat

284 producing elements in the crust) both of which are often lacking (e.g., Rudnick et al.,

285 1998). Moreover, Rudnick et al. (1998) demonstrated the non-uniqueness in this

286 approach; many geotherms "fit" the heat flux data available and it is unclear whether

287 surface heat flux variations are more indicative of variations in crustal heat production or

288 lithospheric thickness. As the Earth cools, the average thickness of the thermal

289 boundary layer increases, and conversely, in the past when the Earth's mantle was

290 warmer, the thermal boundary layer was thinner (Turcotte \& Schubert, 2002). In 
291 addition, local thermal perturbations (for example, due to rifting or mantle upwellings)

292 can thin and weaken the thermal boundary layer. Once the thermal perturbation has

293 dissipated, the thermal boundary layer will thicken as the region cools. Thus, variations

294 in the thickness of the thermal boundary layer can also indicate variations in age, either

295 absolute age as in the case for the oceanic lithosphere (e.g., Müller et al., 2008) or in

296 the amount of time since the last tectono-thermal event in the case of the continental

297 lithosphere.

298

299 The lithosphere can also be described as a compositionally distinct region, often

300 referred to as the chemical boundary layer. Specifically, the strength of the lithosphere

301 can be explained not only by cooler temperatures, but also by increased buoyancy and

302 viscosity driven by compositional differences (often explained as a consequence of melt

303 depletion during crust formation (e.g., Pollack, 1986)). As such, the base of the

304 lithosphere is demarcated by a compositional (and rheological) change and efforts to

305 map out lithospheric thickness under this premise must be sensitive to composition.

306 Mantle xenoliths have traditionally been used for this purpose (e.g., Rudnick et al.,

307 1998; Lee et al., 2011). In addition to compositional information, mantle xenoliths also

308 provide a direct sampling of the temperature and pressure conditions of the regions

309 from which they erupted. Coupled with surface heat flux measurements (as discussed

310 above), mantle xenoliths can be used to discriminate between the possible geotherms

311 as derived from Fourier's law and energy conservation (Figure 3B). The base of the

312 lithosphere is then determined as the depth where the xenolith-determined geotherm

313 intersects the mantle adiabat. 
315 Defining the lithosphere in this fashion assumes that the layer is chemically distinct from

316 the convecting mantle. Jordan $(1975 a, 1978)$ pioneered this idea to explain the

317 observation that cratons are neutrally buoyant despite their cold and old interiors.

318 Following the thermal boundary layer approach, Jordan (1975a, 1978) demonstrated

319 that if continental and oceanic lithosphere were the same composition, there would be

320 mass excess underneath continents that is not observed in the global free air gravity

321 anomaly maps. The thermal analysis in cratonic regions indicated cool temperatures

322 extending to great depths, thus necessitating thick continental lithosphere (Jordan's

323 early estimates extended down to $400 \mathrm{~km}$ (Jordon, 1978)). To reconcile the thermally

324 required thick continental lithosphere with the negligible free air gravity anomaly (and

325 lack of mass excess), Jordan (1975a, 1978) argued that continental lithosphere (in

326 particular, cratonic lithosphere) has a different composition than oceanic lithosphere.

327 This argument was formalized in the "isopycnic hypothesis" (iso=same, pycnic $=$

328 density) which states that at every depth level in the cratonic lithosphere, the negative

329 thermal buoyancy is exactly balanced by a positive chemical buoyancy rendering the

330 region neutrally buoyant (Jordan, 1988). In other words, at each depth, the change in

331 density due to the thermal contraction driven by the temperature difference between the

332 colder cratonic lithosphere and the warmer surrounding mantle is equal to the change in

333 compositional density between the two materials. As the temperature difference

334 diminishes as the geotherm approaches the adiabat, the compositional difference

335 between the continental lithosphere and surrounding mantle also decreases. We

336 should note that isopycnicity is not the same as isostasy. Isostasy describes the vertical 
337 displacement driven by the average density of the entire lithospheric column. Isostasy

338 does provide information about the composition of cratonic lithosphere (isostatic

339 requirements also require positive chemical buoyancy; e.g., Lee et al., 2011;

340 Cammarano et al., 2011), but as a weaker, integral constraint. Isopycnicity, on the other

341 hand, prescribes a compositional stratification based on the thermal structure of cratonic 342 lithosphere.

344 While mantle xenoliths from cratonic regions do possess significant compositional 345 differences from the average mantle whether the compositional difference occur in a 346 strictly isopycnic configuration is still debated (e.g., Lee et al., 2011). Many argue that

347 the compositional distinction and positive chemical buoyancy of cratonic lithosphere 348 were consequences of melt extraction (e.g., Pollack, 1986; Lee et al., 2011).

349 Dehydration was also likely to occur during melt extraction increasing viscosity and 350 contributing to the intrinsic strength of the lithosphere (e.g., Pollack, 1986; Hirth \&

351 Kohlstedt, 1996; Lee et al., 2011). This combination of the positive chemical buoyancy

352 and increased viscosity are suggested to be responsible for lithospheric strength and 353 stability, particularly so in cratonic regions (e.g., Richter 1985; Pollack 1986; Lenardic \& 354 Moresi,1999; Sleep, 2003a; Francois et al., 2013), thus indicating that a chemical 355 boundary layer plays an important role in lithospheric structure.

357 The base of the chemical boundary layer and the thermal boundary layer need not 358 coincide. Estimates for the thickness of the "lithosphere", may differ even in the same 359 region depending on the techniques used (e.g., Jones et al., 2010; Eaton et al., 2009). 
360 Generally, geochemically based estimates (which may be sampling the base of the 361 chemical boundary layer) give thinner values for lithospheric thickness than the seismic 362 observations (which may coincide with the base of the thermal boundary layer) (Lee et 363 al., 2011; Steinberger \& Becker, 2016). These discrepancies indicate that the transition 364 from the surface of the Earth to the convecting mantle is more complex than a single 365 rigid, layer of strength (lithosphere) on top of a weak mantle (asthenosphere). Likely, 366 the transition encompasses several boundary layers whose thicknesses depend on 367 each other. For example, the chemical boundary layer can influence the thickness of 368 the thermal boundary layer (Lenardic \& Kaula, 1996; Cooper et al., 2004; Lee et al., 369 2005). The chemical boundary layer is assumed to be strong, rigid and resistance to 370 deformation (e.g., Pollack, 1986; Lee et al. 2011). As such, heat is transferred through

371 the chemical boundary layer solely by conduction. Small scale convection can occur 372 within the base of the thermal boundary layer allowing for dripping, shearing and 373 deformation of the material. In the scenario where a chemical boundary layer resides 374 within the thermal boundary layer, the thicker the chemical boundary layer, the more it 375 will dominate the conductive, rigid portion of the thermal boundary layer isolating the 376 potentially deformable region to the base of the thermal boundary layer. This deforming 377 region of the thermal boundary layer is often referred to as the convective sublayer. 378 The thickness and temperature drop across the convective sublayer depends on the 379 thickness of the chemical boundary layer (Cooper et al., 2004; Lee et al., 2005).

381 Numerical simulations and theoretical scalings demonstrated that the thicker the 382 chemical boundary layer, the closer it approaches the thickness of the thermal boundary 
383 (Cooper et al., 2004; Lee et al., 2005) in a predictable manner. In other words, the 384 thickness of the chemical boundary layer can be used to predict the thickness of the 385 thermal boundary layer (and correspondingly, the thickness of the convective sublayer) 386 and vice versa. For example, this theoretical relationship was observed, and 387 independently confirmed, within the continental lithosphere of North America using 388 seismic observations (Yuan \& Romanowicz, 2010) indicating that the idea of nested 389 boundary layers might be a good baseline representative for the structure of continental 390 lithosphere. Recognizing this structure within the observations (and any variations both 391 to and within the basic structure) can serve as the first step needed to illustrate

392 processes that build and shape continental lithosphere. In particular, both a better view 393 and conceptual framework for the complexity of the continental lithospheric structure 394 can provide insight into early Earth and the progression into the present day tectonic 395 regime.

397 We should note that there are several other historical approaches to defining and 398 describing the lithosphere (e.g., "seismic lid" - Priestley et al., 2009, "tectosphere" 399 Jordan, 1978, "electric lithosphere" - Jones et al., 2001), but for brevity, we will limit our 400 discussion in this paper to the thermal and chemical boundary layer descriptions of the 401 lithosphere. For more information about the various definitions of the lithosphere, we 402 suggest Eaton et al. (2009), Fischer et al., (2010) and Fischer (2015). Searching for the 403 base of the lithosphere and structure within, whichever definition used, requires a proxy 404 for temperature, composition and/or rheology. Often we turn to seismology to provide 405 that information. In that vein, the lithosphere can also be defined seismologically (e.g., 
406 Fischer, 2015). The seismological lithosphere can also be described multiple different

407 ways, using different techniques as described in the following section, but can generally

408 be defined as the high-velocity outer layer of the Earth, which typically is underlain by a

409 low-velocity layer and/or a distinct change in observed seismic anisotropy. Within this

410 definition, the challenge becomes determining whether this high-velocity layer coincides

411 with the thermal or chemical boundary layer or, perhaps, even some other physical

412 properties.

413

414 In the next section, we describe several seismic imaging techniques as well as

415 showcase observations and interpretations of the internal structure within continental

416 lithosphere.

\section{$418 \quad$ 3. Seismic Imaging}

420 Broadband seismological observations of the continental lithosphere structure provide

421 constraints on seismic velocity, but also estimates of crustal and lithospheric

422 thicknesses, rheological contrasts, presence of anisotropic layers and internal structures

423 that may be related to deformation and/or formation, such as the crustal-mantle

424 boundary (Moho), mid-lithospheric discontinuities (MLDs, defined as seismic

425 discontinuities occurring between the base of the crust and the asthenosphere), or

426 lithosphere-asthenosphere boundary (LAB). Multiple seismological methods are used

427 for imaging the lithosphere, and these techniques include a range of tomographic

428 methods, velocity discontinuity imaging, and various procedures for mapping changes in 
429 seismic anisotropy. Different approaches in seismic imaging have become the subject

430 of serious debate, as new methods are being developed and existing methodologies are

431 improving in order to exploit the continuously growing, enormous volumes of readily

432 available broad-band data for analysis. Varying approaches and tools are designed for

433 different targets, and a few of those commonly used for lithosphere-scale imaging are

434 briefly summarized here. For a more thorough review, see Fischer (2015).

435

3.1 Seismic tomography

438 Global body wave tomography studies robustly image long wavelength ( 100 s of

439 kilometers) lateral features in the upper (and lower) mantle (see Becker \& Boschi (2002)

440 for a summary) with travel-times, highlighting the contrast in velocities and attenuation

441 not only beneath the oceans, but between the active tectonic regions of the continent

442 and their stable cores (cratons). However, due to the near vertical incidence of

443 teleseismic body waves used in P-wave inversions, the depth of the lithosphere is often

444 over-estimated when only P-waves are used. Furthermore, crustal scale velocity

445 perturbations can be difficult to resolve with teleseismic data and global inversions. In

446 addition, the wavelength of structures imaged with global body wave tomography,

447 whether or not they include surface waves in the inversion, are typically not at the scale

448 needed (1-10s of kilometers) to investigate the detailed internal structure of the

449 lithosphere. 
451 Global surface wave tomography, however, is often used to infer the absolute shear452 wave velocity structure of the upper mantle and through analysis of various periods of

453 horizontally propagating surface waves. Due to the inherent difference in the types of 454 seismic waves used, there generally is not as much vertical smearing of the velocity 455 structure as is common with body wave tomography. However, due to the integrative 456 properties in surface wave tomography, near-horizontal boundary structures, such as 457 the Moho and LAB can be difficult to image. Joint inversion of S-waves and surface 458 waves (and also normal modes) for global shear wave velocity perturbations provide 459 some of the most comprehensive tomographic models of the upper mantle (e.g., 460 Schaeffer \& Lebedev, 2013; French et al., 2013). These models clearly identify 461 subduction zone structures, the difference in thickness of the lithosphere in cratonic 462 environments versus active tectonic regions, and also clearly image the smaller-scale 463 variations in structure within the continental lithosphere as shown in Figure 4, which 464 approach regional scale studies (Schaeffer \& Lebedev, 2013). 


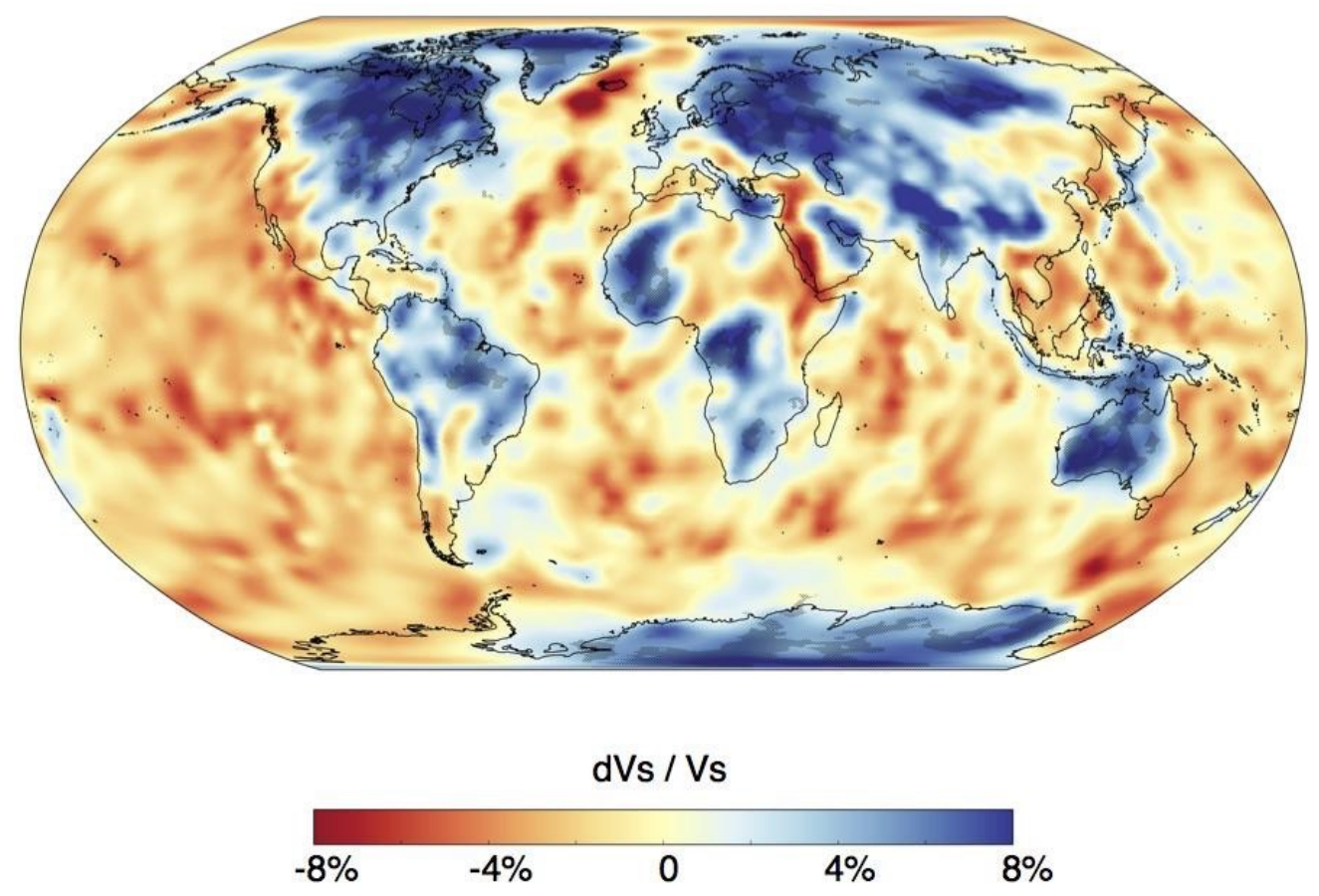

Figure 4. Global S wave tomography model by Schaeffer \& Lebedev (2013) plotted at $150 \mathrm{~km}$ depth. The additional

472 Regional tomography studies can provide more detailed images of the structure of the

473 continental lithosphere, and with the ever increasing number of seismic stations the

474 images are constantly improving. Travel-time tomography using only body wave

475 arrivals at densely spaced arrays, such as USArray, have provided "high" resolution

476 images $(\sim 10 \mathrm{~km})$ that show the incredible complexity of the continental lithosphere

477 beneath the Moho (see Becker (2012) for a summary). Continent-scale surface wave

478 models (of North America) also clearly illustrate the large (and regional) scale variations

479 in structure (10-100s of kilometers), but more focused studies that use either ballistic

480 (e.g., Wagner et al., 2010; Pollitz \& Mooney 2016) or ambient noise (e.g., Lin et al.,

481 2009; Porritt et al., 2011) surface waves techniques confirm this observation and further 
482 illustrate that the continental lithosphere is extremely heterogeneous and complex at the $483 \sim 10 \mathrm{~km}$ scale within both the crust and mantle lithosphere. Similarly, surface wave 484 images of the other continents show lithospheric complexity where there have been 485 extensive seismic deployments such as in Europe (e.g., Zhu et al., 2012) or China (e.g., 486 Bao et al., 2015), and Australia (e.g., Saygin et al., 2012; Fishwick \& Rawlinson 2012). 487

\subsection{Discontinuity structures}

Layering within the continental lithosphere has long been known (e.g. Mohorovicic,

491 1910; Gutenberg, 1948; Lehmann, 1961; Hales, 1969), but the complexity, layering, and

492 structures within the outer layer of the Earth continues to be to revealed with seismic

493 scattering and discontinuity imaging (e.g., Gaherty \& Jordan 1995; Bostock 1998;

494 Rychert et al., 2007; Savage et al., 2008; Rychert \& Shearer 2009; Abt et al., 2010;

495 Miller \& Eaton 2010). Receiver function analysis (Langston, 1977; Vinnik 1977; Farra \&

496 Vinnik 2000) has become an important tool in mapping sub-horizontal velocity

497 discontinuities in the crust and mantle. P receiver functions (PRFs), which use P-to-s

498 conversions, are commonly used to map the crust-mantle boundary (Moho) and internal

499 crustal structure and are less commonly used for deeper structure due to the potential

500 contamination of crustal multiples at deeper lithospheric depths (Rychert \& Shearer,

501 2009). The raw Ps signal is often weak and so the RFs are generally stacked to

502 improve the signal-to-noise ratio. Then the stacked RFs represent the 1-D (generally)

503 isotropic structure below a seismic station, where the phase delay between P and Ps

504 indicates the depth of discontinuity it arises from, and the amplitude represents the 
505 strength of the impedance contrast at that boundary. S receiver functions (SRFs),

506 which instead use S-to-p conversions, are also a powerful tool for imaging deeper

507 subhorizontal structures such as the lithosphere-asthenosphere boundary (LAB) or mid-

508 lithospheric discontinuities (MLDs) as the signals are not contaminated by crustal

509 multiples, but are limited by their lower frequency content and smaller distance range for

510 appropriate teleseismic events (Yuan et al., 2006). With densely spaced seismometers,

511 more sophisticated methodologies can be used with teleseismic scattered phases to

512 produce either 2D (Bostock 1998; Frederiksen \& Bostock 2000) or 3D images (Dueker

513 \& Sheehan, 1997) of seismic discontinuities (Rondenay et al., 2005). All these flavors

514 of receiver functions are useful for mapping sharp velocity discontinuities and can

515 provide tight constraints $(\sim 1 \mathrm{~km})$ on the depth of these structures. Recent literature has

516 provided global compilations of results that map the internal structure of the continental

517 lithosphere (Fischer et al., 2010; Cooper \& Miller, 2014; Hopper et al., 2014; Selway et

518 al., 2014; Rader et al., 2015), which are shown in Figure 6.

\subsection{Anisotropic structures}

521

522 Another seismic observable used to infer deformation within the continental lithosphere

523 and its base is through the detection of seismic anisotropy, which is defined as the

524 dependence of seismic velocities on the direction of wave propagation and polarization.

525 Changes in anisotropy within the continental lithosphere have also been mapped with

526 multiple methods which include, but are not limited to, receiver functions, shear wave

527 splitting, and surface wave tomography. In the oldest centers of the continents, seismic 
528 anisotropy can often be linked to fossil mantle textures, dating from rifting, collision, and

529 accretion events during the formation of the lithosphere (Park \& Levin 2002; Yuan \&

530 Romanowicz, 2010), but this interpretation is far from simple or widely-proven for

531 different regions or even observed globally (Fouch \& Rondenay, 2006; Long \& Becker

532 2010).

533

534 For an isotropic, flat-layered Earth structure, tangential component receiver functions

535 should be zero (or contain only incoherent noise in reality), and the radial component

536 receiver function should have signals that are independent of back azimuth and then

537 used to image the discontinuity structures beneath seismic stations as discussed above.

538 However, in practice, coherent and azimuth-dependent signals are observed on both

539 the radial and tangential component receiver functions, which can be used to infer

540 anisotropic structures using a variety of techniques (Bostock, 1998; Savage,1998;

541 Frederiksen \& Bostock, 2000; Schulte-Pelkum et al., 2014). Receiver function analysis

542 of anisotropy can detect sharp vertical variations in anisotropy and dipping layers with

543 better resolution than the other methods discussed here (Fouch \& Rondenay, 2006), but

544 are limited by non-linearity and densely spaced seismic stations.

546 Shear wave splitting analyses, in particular splitting of core phases (SK(K)S), are based

547 upon the properties of birefringence of nearly vertically propagating shear waves

548 beneath seismic stations. The lateral measurements (at multiple stations) of splitting of

549 SKS phases allow for interpretation of the back-azimuthal variation of delay times and

550 fast directions to infer the presence of anisotropic layers or dipping structures in the 
551 mantle, however the depth constraints of these layers is poorly resolved due to the

552 path-integrated effect of anisotropy from the core to the crust (Silver \& Chan, 1988;

553 Fouch \& Rondenay 2006).

554

555 Two types of seismic anisotropy, azimuthal (horizontal) and radial (vertical) anisotropy,

556 can be measured with surface wave methodologies. Radial anisotropy in the upper

557 mantle has been detected with the discrepancy between Rayleigh and Love wave

558 propagation, while the existence of azimuthal anisotropy is determined by changes in

559 directional dependence of the propagation of Rayleigh waves. A major advantage of

560 using surface waves to detect continental lithosphere anisotropy is that the depth of the

561 anisotropic layers are much better constrained than when using body wave (e.g. SKS)

562 measurements. For example, detecting azimuthal anisotropy in the upper mantle from

563 surface waves can illustrate how the orientation of the fast axis of anisotropy changes

564 with depth with more widely spaced stations than with receiver function methods. Many

565 different methods can be used to infer both radial and azimuthal anisotropy within the

566 continents (see Fouch \& Rondenay (2006) and Fischer (2015) for reviews).

568 Further advances are rapidly being made to improve imaging capabilities by jointly

569 inverting different types of data and results, integrating existing models as starting

570 models, utilizing full waveform inversions, developing array based methods, and

571 exploiting faster computational abilities (Julià et al., 2000; Sigloch 2011; Yang et al.,

572 2011; French et al., 2013; Shen et al., 2013; Porritt et al., 2014; Schmandt \& Fan-Chi

573 2014; Calò et al., 2016). These rapid developments have produced detailed structural 
574 images of the continental lithosphere that are providing new observations of the

575 complex formation and deformation that has occurred throughout geologic history.

576

$577 \quad 3.4$ Seismic observations

578

579 Regardless of the seismic imaging technique, there is a first-order feature that is

580 observed in continental lithospheric structure. The oldest cores of the continents have

581 thicker, fast velocity structure; in contrast, the younger regions of the continents have

582 much thinner lithosphere (Figure 5). Global seismic observations (Figure 4) illustrate

583 that the thick cratonic mantle lithosphere has high velocity in comparison to the same

584 depths beneath the Phanerozoic lithosphere. Some petrological studies suggest

585 compositional variations between two age groups (e.g., Poudjom Djomani et al., 2001),

586 however, recent seismic studies have suggested that there is no systematic difference

587 in the velocity and overall thickness between the Proterozoic and Archean lithosphere

588 (Darbyshire \& Eaton, 2010).

589

590 More detailed, regional seismic observations illustrate the complexity of the deep

591 continental lithosphere structure both in the cratons and in the tectonically active

592 regions. Regional studies of active convergent margins, for example, image the

593 subducted oceanic lithosphere but also image how the overriding continental

594 lithosphere is deformed and formed by the subduction zone processes (e.g., Gutscher

595 et al., 2000; Humphreys 2009; Schmandt \& Humphreys 2010; Miller \& Agostinetti 2011;

596 Porritt et al., 2011; Schmandt \& Humphreys 2011; Pearce et al., 2012; Levander et al., 
597 2014; Kim et al., 2014; O’Driscoll \& Miller 2015). In the shallow mantle lithosphere a 598 few high-resolution studies have imaged the dipping subducted oceanic lithosphere, 599 mantle wedge and modified structure of the overriding plate (e.g., Bostock et al., 2001;

600 Pearce et al., 2012; Kim et al., 2012; Bostock, 2013), accreted terranes such as the 601 actively subducting Yakatut beneath Alaska (Ferris et al., 2003; Rondenay et al., 2010;

602 Kim et al., 2014), the 55 Ma Siletzia terrane stagnating in the upper mantle beneath 603 northwestern United States (Schmandt \& Humphreys, 2011), and collision of continental 604 lithosphere transferred to base of the overriding plate (Eurasia) in the Banda arc of 605 southeast Asia (Porritt et al., 2016). Inboard of subduction zones, but in regions that 606 are still considered tectonically active like the western Americas and the Mediterranean

607 the continental lithosphere continues to be deformed and modified by tectonic 608 processes (van der Hilst \& Paul 1994; Wortel \& Spakman 2000; Gilbert et al., 2006;

609 Schmandt \& Humphreys 2010; Levander \& Miller 2012; Bao et al., 2014).

610 

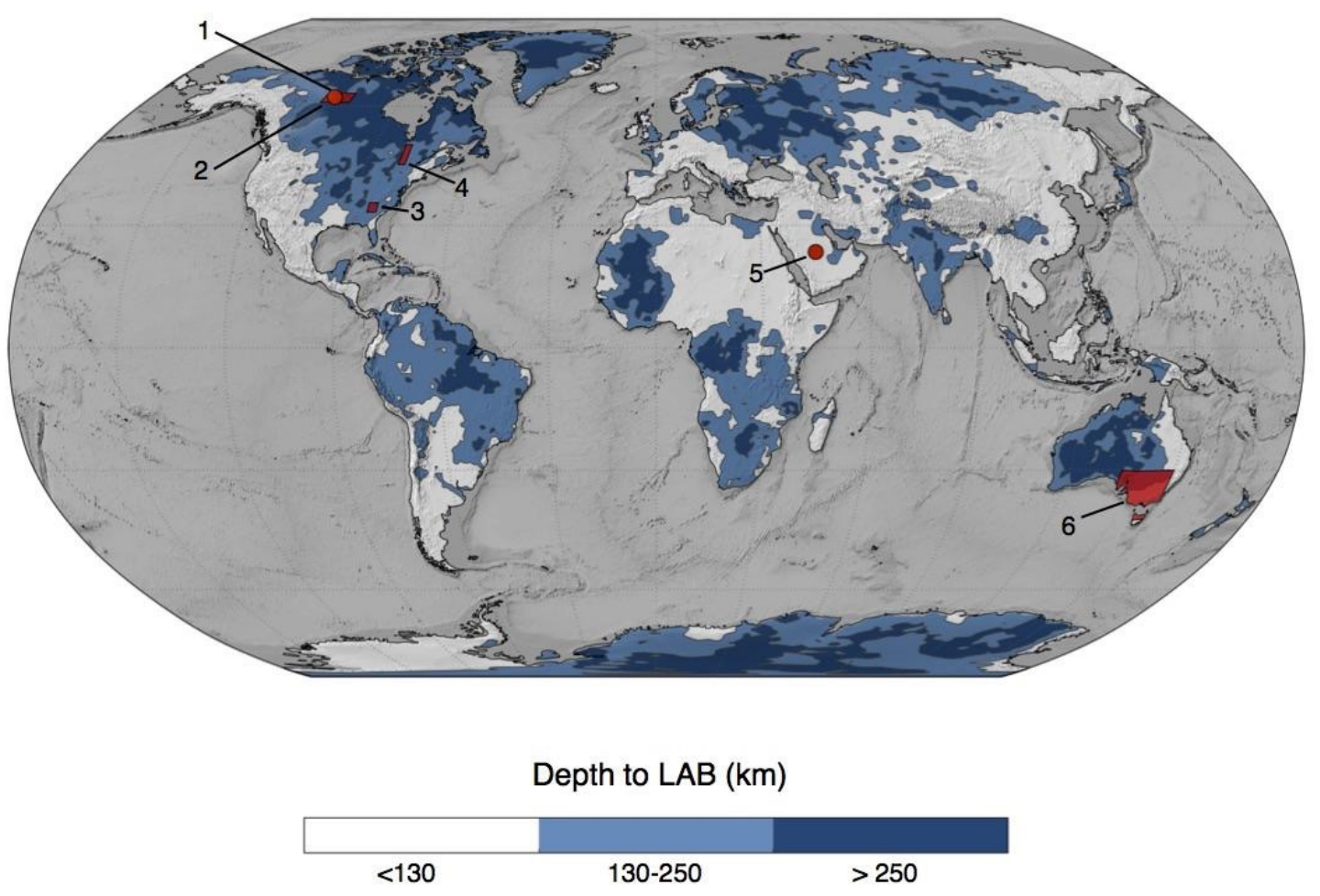

611

612 Figure 5. Contours of continental lithosphere thickness taken from the litho1.0 model (Pasyanos et al., 2014). Dark

613 blue are the regions thicker than $250 \mathrm{~km}$ and lighter blue are regions between 130 and $250 \mathrm{~km}$ in thickness. Thinner

614 regions have not been colored. The background is shaded relief computed for ETOPO1 (Eakins \& Amant,e 2009).

615 Red polygons indicate the locations of broadband seismic studies that observe structures that have been interpreted

616 to be ancient accreted terranes / terrane boundaries preserved within the continental lithosphere (1 - Bostock,1998; 2

617 - Cook et al., 1998; 3 - Parker et al., 2015; 4 - Rondenay et al., 2000; 5 - Levin \& Park, 2000; 6 - Pilia et al., 2015).

618

619 Away from convergent margins, within the continental interiors, structures imaged seem

620 to be as complex and appear to have characteristics that are reminiscent of modern

621 accretionary structures. Ancient accreted terranes and sutures have been mapped

622 geologically (e.g., Oldow et al., 1989; Betts et al., 2011), and have been mapped by a

623 few active source based studies (BABEL Working Group 1990; Cook et al., 1999;

624 Magnani et al., 2004). Large scale active source seismic experiments, such as

625 Lithoprobe (Hammer et al., 2010), were able to image lithospheric structure across the 
626 entire North American continent from active subduction in the west to the cratonic

627 interior. These efforts provide a link between the structures in the active tectonic

628 regions and those in the stable continental interior. Passive source seismology has also

629 been able to image the structures within the continental lithosphere with impressive

630 resolution $(<1-1 \mathrm{~km})$ in select locations (red polygons in Figure 5).

632 One of the first studies linked the active and passive source seismological experiments

633 in the Slave craton of Canada (Bostock, 1998). This study imaged dipping reflectors

634 from P-to-s conversions that correlate with the shallow reflectors from the Lithoprobe-

635 SNORCLE active source experiment (Cook et al., 1999) interpreted as tectonic

636 boundaries or sutures,suggesting that subduction-like processes were fundamental in

637 assembling the continental lithosphere. Similarly, on the southeastern edge of the

638 Canadian shield, Rondenay et al. (2000) image a subduction zone suture at the

639 Grenville Front using a combination of tomography, SKS splitting, and receiver function

640 techniques. Recently, in the southern Appalachians, receiver functions were used to

641 observe a décollement beneath the fold-thrust belt that transitions into a subhorizontal

642 shear zone inward toward the orogen. This was interpreted as a set of accreted terranes

643 overlying the basement rocks (Parker et al., 2015).

644

645 In southeastern Australia, Pilia et al. (2015) found evidence of discrete terranes within

646 the continent that were accreted in the Paleozoic. The fabric of the accreted terrane

647 geometries and deformation history is inferred from seismic anisotropy derived from

648 ambient noise tomography (Figure 9B). Their results suggest that exotic continental 
649 fragments from Paleozoic collision of terranes onto the Proterozoic and Archean core of

650 the Australian continent are preserved and identifiable. Other less well sampled regions

651 on Earth, also suggest the presence of dipping, anisotropic layers in other continental

652 cratons. For example, one study of the Arabian shield also imaged dipping, anisotropic

653 discontinuities in a similar depth range $(\sim 80 \mathrm{~km})$ with one seismic station, which could

654 be related to shear zones formed during Proterozoic continent-continent collision (Levin

655 \& Park, 2000).

656

657 More widespread surveys within the continents observe mid-lithospheric discontinuities

658 (MLDs) with S receiver functions (Selway et al., 2015). The mid-lithospheric

659 discontinuity refers to a seismic discontinuity recorded at a depth range of $\sim 80-120$

660 kilometers, which may or may not be related to the Hales discontinuity or those imaged

661 by the detailed scattered wave images mentioned above. Initially, the MLDs were only

662 identified in sparse locations within the cratons of North America, Australia, and Africa,

663 due to the wide, uneven distribution of broadband seismic stations $\sim 10$ years ago e.g.

664 (Wittlinger \& Farra 2007; Olsson et al., 2007; Savage et al., 2008; Abt et al., 2010; Miller

665 \& Eaton 2010; Ford et al., 2010; Cooper \& Miller 2014). As the number of evenly

666 spaced stations increased and additional methods of imaging became available and

667 adapted to the growing volume of data, the number and distribution of MLDs

668 dramatically increased (Figure 6). Furthermore, in some places are the MLDs are

669 observed at multiple depths (Figure 6, inset B, C) within the same region (Yuan \&

670 Romanowicz 2010; Lekić et al., 2014; Hopper et al., 2014; Hopper \& Fischer 2015;

671 Porritt et al., 2015; Hansen et al., 2015; Calò et al., 2016) and are represented by (most 
672 often) a negative velocity gradient, but occasionally a positive velocity gradient at similar

673 depths. Figure $6(D, E)$ shows the distribution of the MLDs with lithospheric thickness

674 and compares this to the global distribution of lithospheric thickness, showing that $80 \%$

675 these features are generally only seen in the thickest $20 \%$ (175 km or more) of the

676 continental lithosphere.

677

678

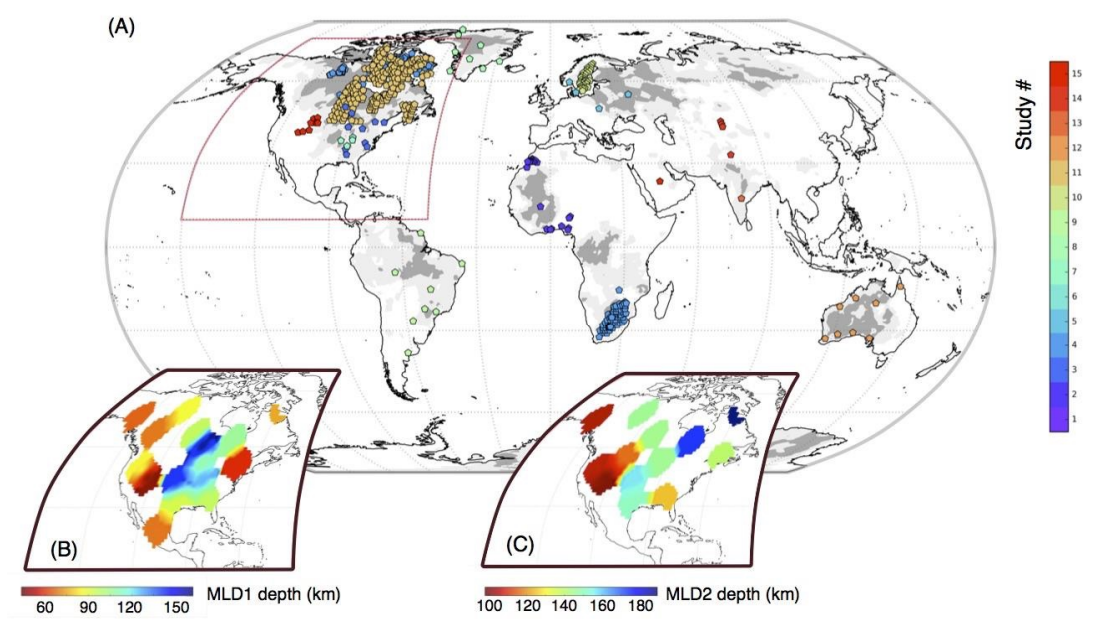

(D)

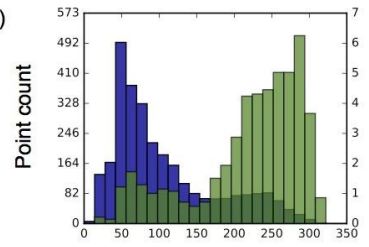

(E)

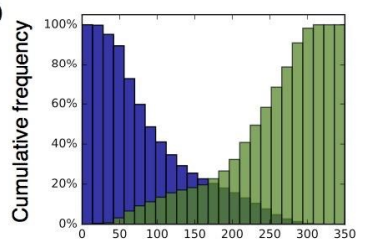

679

680

681

682

683

684

685

686

687

688

689

690

Figure 6. (A) Global compilation of observations of S receiver function based mid-lithosphere discontinuities (MLD), color coded by provenance (see text for references) the shading indicates lithospheric thickness in two bands: light gray for lithosphere more than $150 \mathrm{~km}$ in thickness, and dark grey for more than $250 \mathrm{~km}$ thickness (litho1.0,

Pasyanos et al., 2014). (B,C) are representations of the depths of two mid lithosphere discontinuities (MLD1 and MLD2) imaged by Calò et al. (2016). Gaps in the interior of this study indicate regions where the discontinuity surface is absent. (D) Frequency count for the thickness of the lithosphere taken at every point in the litho1.0 model (blue and left axis), and for those points where MLDs have been identified in (green and right axis). (E) Cumulative frequency diagram for the same information (global lithospheric thickness, blue, from thick to thin) and for the lithosphere at locations in (A) where an MLD observation has been made (green, cumulative from thinner to thicker). The litho1.0 model is an icosohedral triangulation of the sphere at approximately 1 degree separation. The MLD information was 
projected to the nodes through a weighted average and only those nodes with at least one observation within their

692 local support were counted in the histogram. No additional weight was given to multiple observations near any point.

694 Although the stable interiors of the continents are generally thicker (Figure 5), the base

695 of the lithosphere is not observed at a uniform depth. There are differences between each continent and even within an individual craton. For example, the North American

697 craton, which is one of the most well-studied regions, illustrates this point. Beneath the 698 core of the continent as seen in the high velocity structures in Figure 4, around Hudson 699 Bay there is significant variation in the depth ( 200 - $325 \mathrm{~km})$ to the LAB (Figure 5) from 700 seismic observations (Darbyshire \& Eaton 2010; Porritt et al., 2015). The variation in 701 thickness and structure has been interpreted from broadband seismic studies to be a 702 signature of Archean-Paleoproterozoic tectonics, and the formation of the Trans-

703 Hudson orogen around 1.8 Ga when several Archean terranes were assembled into 704 what is now the Canadian Shield (Bastow et al., 2010). Similarly, the African continent, 705 particularly the South African craton, displays a significant variation ( 100 to $>300 \mathrm{~km})$ 706 in the lithospheric thickness (e.g. Wittlinger \& Farra 2007; Fishwick 2010; Cooper \& 707 Miller 2014) indicating that the sequential tectonic assembly of the continent is reflected 708 in the structure of the individual cratons (Begg et al., 2009).

710 The continental lithosphere imaged with broadband seismic data suggests that the

711 internal structure, including multiple layers (Moho and MLDs), variable depth to the base 712 of the lithosphere (LAB), and dipping structures, is indicative of the long-term evolution 713 and formation of both the youngest and oldest part of the continents. 


\section{4. Dynamic Interpretation of Lithospheric Structure}

717 The techniques discussed above and observations from the global maps highlighted in

718 Figures 1-6, while deeply informative, offer only a static view of the continental

719 lithosphere. What we "see" in these data sets is the sum of all of the geologic events 720 and processes occurring over the history of a region (often spanning millions to billions

721 of years). While the data sets are used to unravel the tectonic events through careful

722 interpretation, further insight can be gained through geodynamic modeling. In

723 particular, geodynamic modeling can help guide our interpretation and determine

724 whether modern and ancient processes produce similar or different lithospheric

725 structure.

726

727 As mentioned above, considerable debate revolves around the style of tectonics that

728 operated during the Archean and Proterozoic, when much of the continental lithosphere

729 was formed. The exact timing of the onset of plate tectonics and modern subduction is

730 unresolved (e.g., Furnes et al., 2007; Chen et al., 2009; Smart et al., 2016). Therefore,

731 it is unclear whether the processes that currently shape the continental lithosphere were

732 active and operating in the same manner that they do today. Several hypotheses have

733 been proposed for cratonic lithosphere formation, and they can be categorized into two

734 groups: (1) those that invoke processes unique to the pre-plate tectonic Earth and (2)

735 those that call upon modern day plate tectonic processes. Each offer an explanation for

736 the observed stability of cratonic lithosphere as well as the basic structure of a chemical

737 boundary layer residing within the thermal boundary layer. These hypotheses should 
738 also be able to provide context for the geochemical and seismological observations of

739 cratonic lithosphere. Furthermore, each must also account for the longevity of cratonic

740 lithosphere which is different than solely describing stability.

742 Regardless of the exact dynamic regime, the conditions experienced by cratonic

743 lithosphere will change with time after formation. For example, convective stresses

744 increase as the Earth cools. This is due to the dependency of the mantle's viscosity on

745 temperature - as the Earth cools, the average mantle temperature decreases and the

746 viscosity increases which nets in increased convective stresses (e.g., Cooper \& Conrad,

747 2009; Sandu et al., 2011). In addition, the condition of isopycnicity, which explains the

748 present day neutral buoyancy of cratonic lithosphere, may not have been met in the

749 past when the mantle was hotter and the average thermal boundary was thinner (Eaton

750 \& Perry, 2013). Thus, creating stable and long-lived cratonic lithosphere requires

751 producing a feature that can resist deformation shortly after formation and from that

752 moment onward. The longevity issue prompts some to propose that the composition of

753 cratonic lithosphere can only be produced during the early Earth (O'Reilly et al., 2001;

754 Poudjom Djomani et al., 2001) or that cratonic lithosphere is preferentially buffered from

755 deformation by surrounding, slightly weaker material (Lenardic et al., 2000; Cooper \&

756 Conrad, 2009).

758 We do note that there is evidence that some cratonic regions have not survived to

759 present day (e.g., Gao et al., 2004; Abdelsalam et al., 2011; Guo et al., 2016). This

760 does hint at the possibility that whatever processes form cratonic lithosphere may not 
761 always succeed in building long-lasting stable features. However, for the scope of this

762 paper, we limit our discussion to creating and preserving, rather than destroying,

763 cratonic lithosphere.

764

765 Here we outline the arguments for the formation hypotheses as well as outline the

766 predicted lithospheric structure produced by each as well as their explanations for

767 stability and longevity. We will consider these within the framework of the observations

768 made in the previous section as well as critically evaluate their potential to form long

769 lasting, stable lithosphere containing complex structures.

770

7714.1 Hypotheses based on a pre-plate tectonic regime

772

773 Much of the debate surrounding the onset of plate tectonics depends on the uncertainty

774 as to how different parameters respond to higher mantle temperatures in the past.

775 Several of the ideas for cratonic formation call upon processes that would only be in

776 operation during times of higher average mantle temperatures. This has the benefit of

777 explaining the seemingly uniqueness of craton lithosphere, but, in some cases, removes

778 the advantage of correlation to modern day processes. The majority of the pre-plate

779 tectonic ideas centralize around primarily vertical motion (Figures 7A \& B), as large-

780 scale lateral motion is more indicative of the plate tectonic regime. As such, the

781 lithospheric structure produced in such settings would be indicative of processes driven

782 by upwellings, drips and/or regional lateral motion (in response to isostatic adjustments

783 or gravitational collapse). 
785 An early idea for craton formation invoked large and deeply seated melting events 786 caused by large mantle plumes (Figure 7A) or upwellings (e.g., Pearson et al., 1995;

787 Robin \& Bailey 2009; Aulbach, 2012). It is suggested that the melting occurred through 788 a large single event triggered by a plume (e.g., Pearson et al.,1995). It is speculated 789 that, in the early Earth, the hotter mantle temperatures allowed for incipient melting to 790 occur at greater depths within a plume (e.g., Lee et al., 2011). This would provide a 791 large enough melting event to produce residuum up to several hundreds of kilometers 792 thick. In addition, the higher temperatures promote higher degrees of melting such that 793 the residuum is strongly depleted and dehydrated. This provides the means to make 794 thick, buoyant and highly viscous cratonic lithosphere in a single event. The argument 795 for a single melting event centers around the similar crustal and lithospheric ages in 796 some cratons indicating a coupled origin (e.g., Pearson et al.,1995; Carlson et al., 2000;

797 Griffin et al., 2003; Carlson et al., 2005). Other geochemical evidence, however, argues 798 that the melting associated with cratonic lithosphere occurred at lower pressures (e.g., 799 Lee, 2006) which calls into question the plume driven large, single melting event.

801 Others have suggested that the cratonic lithosphere was formed through diapirism and 802 vertical tectonics where dense volcanic material is moved vertically deeper into the 803 mantle in response to a density inversion (Figure 7B). In this scenario, cratonic crust 804 and lithosphere is made through successive sorting events. Robin \& Bailey (2009) 805 assumed that this process was driven by an unstable compositional stratification 806 caused by the emplacement of mafic volcanics on top of felsic crust. The density 
807 inversion and incubation of the more radiogenic felsic crust could drive ductile

808 deformation and the development of domes and keels (Sandiford et al., 2004). Robin \&

809 Bailey (2009) argue that the cratonic lithosphere could have formed by the successive

810 vertical accumulation of the residuum generated from melting the mafic volcanics that

811 moved downward during the keeling process or from melting driven from delamination

812 events often referred to as "sagduction" (Bédard, 2006; Bédard et al., 2013). While the

813 diapirism can explain the dome and keel structure of some Archean crust (e.g.

814 Sandiford et al., 2004) and potentially provides an explanation for the coeval evolution

815 of the crust and lithosphere, it has not yet been demonstrated that it is possible to form

816 a root several hundred kilometers thick through the vertical migration of dense melts.

(A)

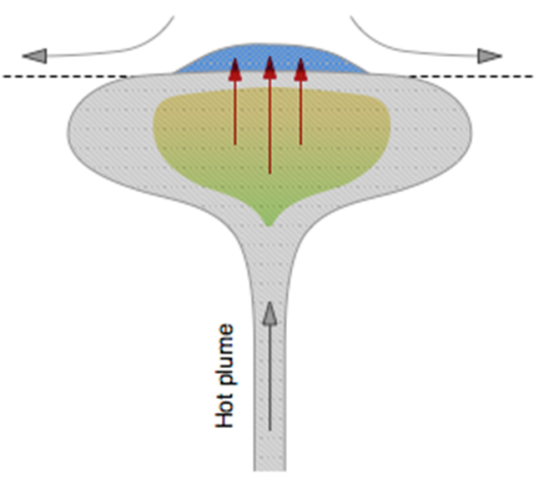

(C)
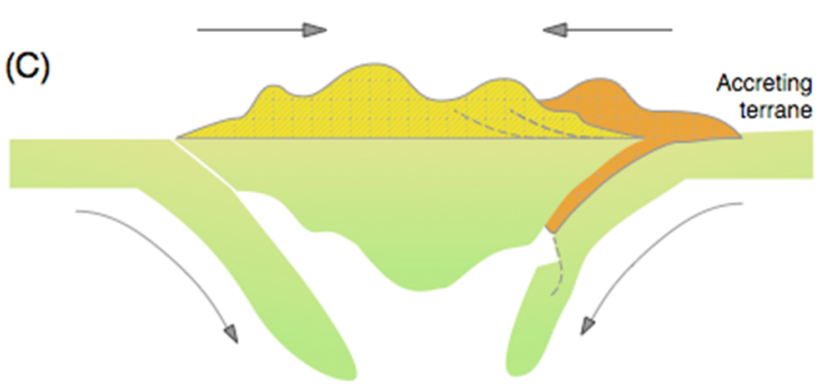

Subducting slabs
(B)

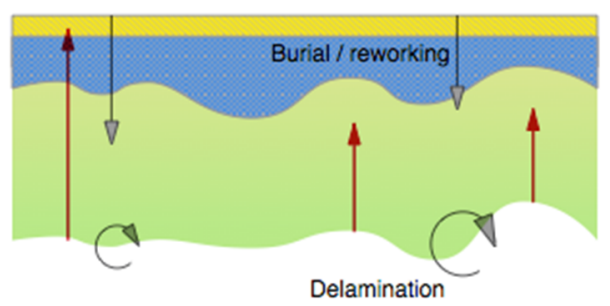

(D)

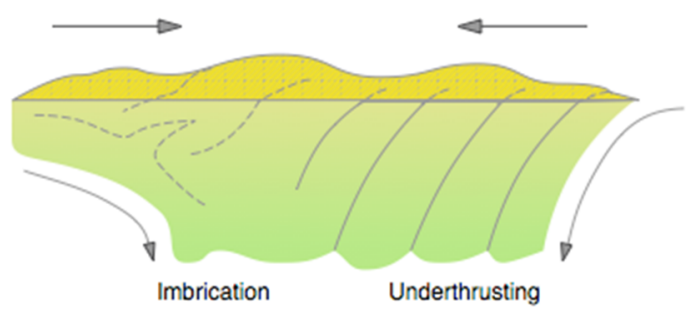

Depleted peridotite

Felsic Crust

Micro-continent / Arc terrane

Basalt / Komatiite 
Figure 7. Conceptual sketches of craton formation. Gray arrows show sense of motion. Red arrows indicate melt

818 transport. (A) Melting event trigger by large mantle plume as described in Pearson et al., (1995) and Lee et al.,

819 (2011). (B) Burial/reworking and sorting of dense materials (e.g., Robin \& Bailey, 2009; Moore \& Webb, 2013; Sizova

820 et al., 2015). Though not explicitly shown in this sketch, diapirism can further aid the resorting of dense materials.

821 (C) Lithospheric thickening through the amalgamation of arc material (e.g., Jordan, 1978). (D) Thrust stacking and

822 imbrication of buoyant oceanic lithosphere (e.g., Bostock, 1998).

824 Similarly, another proposed tectonic setting for the early Earth, the heat pipe regime,

825 allows for the rapid removal of heat through pervasive, localized volcanism as well as

826 the development of thick lithosphere via vertical transport. It was first proposed to

827 explain heat loss on Venus and lo (e.g., Turcotte 1989; Armann et al., 2012; Moore

828 2001), both terrestrial bodies demonstrating little horizontal motion, but significant

829 volcanism. The heat pipe mode allows for efficient cooling of the hot interiors (e.g. as

830 induced by tidal heating in the case of lo or heat from the decay of radioactive elements

831 for Venus(e.g., Turcotte 1989; Armann et al., 2012; Moore 2001)) without invoking plate

832 tectonics. This idea was extended to the early Earth to explain the removal of heat in

833 conditions wherein plate tectonics might not be operating. The early Earth's mantle was

834 hotter in the past due to the higher amount of radioactive elements and residual heat

835 from the formation of the planet, yet early estimates of the temperature gradient across

836 the lithosphere suggests surface heat flux values similar to present day (Burke et al.,

837 1978). During a heat pipe mode of convection, the entire surface acts as a single plate

838 and rapid, localized volcanic eruptions connect, as "pipes", the hot, convecting mantle to

839 the surface, effectively removing heat. The volcanic eruptions pile up on the surface

840 burying cooler regions of the lithosphere and thus, building a cool, thick lithosphere

841 even in the midst of a hotter mantle. Depending on eruption rates, the rapid and 
842 successive volcanism described in Moore \& Webb (2013) might also explain the

843 observation of coeval cratonic crust and lithosphere (e.g., Pearson et al., 1995; Carlson

844 et al., 2000; Carlson et al., 2005). This process also would promote melting at shallow

845 depths satisfying the geochemical requirement for low pressure melt production (Lee,

846 2006). In a modified form of the heat-pipe hypothesis, which included the possibility of

847 intracrustal melting in addition to rapid volcanism, Sizova et al. (2015) demonstrated

848 that eruption of melts followed by their burial and dynamic overturning could generate

849 the observed Archean crustal composition and depleted mantle lithosphere.

851 An additional formation hypothesis that could have also operated within (or as a

852 consequence from) a heat pipe or other early Earth tectonic regimes calls upon the

853 gravitational collapse of thick lithosphere (Rey et al., 2014). This idea proposes the

854 surface of the Earth, though immobilized by stagnant lid convection, is divided into

855 regions of thick, continental lithosphere and oceanic lithosphere. The authors propose

856 that variations in the thickness of the early lithosphere could have driven horizontal

857 gravitational forces sufficient to cause yielding of the adjacent thinner oceanic

858 lithosphere simultaneously initiating subduction and collapse within the continental

859 lithosphere (Rey et al., 2014). The gravitational collapse initiates decompression

860 melting at the base of the continental lithosphere. This melting event introduces

861 depleted residue at the base of the thinned continental lithosphere. In this model, the

862 lithosphere continues to thicken and strengthen via cooling. The authors also propose

863 that as subduction develops, the cratonic lithosphere along the newly formed margins

864 will experience metasomatism further characterizing the geochemical signature of

865 cratonic lithosphere (Rey et al., 2014). This hypothesis depends on the assumption of 
866 pre-existing regions of thick and buoyant cratonic lithosphere. The authors argue that

867 these regions would have formed by differentiation within buoyant oceanic plateaus

868 (possibly akin to the dome and keel behavior) (Rey et al., 2014). There is also

869 significant tradeoff between rheological parameters of the initial cratonic lithosphere and

870 oceanic lithosphere necessary to allow for the gravitational collapse and subsequent

871 initiation of subduction. The initial cratonic lithosphere needed to be strong enough to

872 maintain a thickness differential, but weak enough to eventually, catastrophically

873 collapse. Regardless, this mechanism does provide a unique and one-off scenario to

874 form thick and stable cratonic lithosphere without invoking plate tectonics.

875

876 All of these hypotheses are capable of forming a strong, thick chemical boundary layer

877 residing within the thermal boundary layer. Stability and longevity within these

878 scenarios are provided by the unique composition and rheology induced by the high

879 degree melting. The lithosphere produced by a single, plume melting event would

880 exhibit compositional stratification due to the gradual decline of melt-depletion in the

881 plume structure with depth (e.g., Lee et al., 2011) whereas the others might produce

882 compositional stratification due to the progressive layering of dense residuals (e.g., Rey

883 et al., 2014). All would produce planar structures related to the melting event(s).

884 Recently, there has been observational evidence for a mid-lithospheric discontinuity

885 (MLD) in Ontong Java Plateau interpreted as a remnant of the melting event that formed

886 the oceanic plateau (Tharimena et al., 2016). This suggests a mechanism for producing

887 MLDs observed within cratonic lithosphere produced by large melting events associated

888 with plumes or successive volcanic eruptions. However, these hypotheses fail to 
889 describe the more complex nature, mentioned above, of some of the MLDs observed 890 within the cratonic regions that show continuous dipping surfaces (e.g., Bostock, 1998;

891 Miller \& Eaton, 2010) and even multiple MLDs in a single location (e.g., Hopper et al 892 2015; Calò et al., 2016) suggesting a differing origin than melting events alone, at least 893 in those areas.

894

\subsection{Hypotheses based on early development of plate tectonics}

897 There are several lines of evidence that suggest that plate tectonics could have been in 898 operation during formation of the cratonic lithosphere. These range from geochemical 899 signatures of subduction within cratonic mantle xenoliths (e.g., Lee, 2006) to seismic 900 imaging of complex structure deep within the cratonic lithosphere (Bostock, 1998; Miller 901 \& Eaton, 2010; Yuan \& Romanowicz, 2010; Cooper \& Miller, 2014; Wirth \& Long, 2014; 902 Hopper \& Fischer 2015; Calò et al., 2016). Indeed, seismological observations seem to 903 be converging on the idea that the pervasive mid-lithospheric discontinuity observed in 904 the thick, Precambrian lithosphere is a likely relic from formation (Bostock, 1998;

905 Bastow et al., 2010; Miller \& Eaton, 2010; Yuan \& Romanowicz, 2010; Cooper \& Miller, 906 2014; Wirth \& Long, 2014; Hopper \& Fischer, 2015; Calò et al., 2016). In the framework 907 of plate tectonics, cratonic lithosphere was formed by thickening pre-existing lithosphere 908 in a subduction zone setting. Early proponents of this idea suggest that cratons were 909 formed through the thrust stacking of buoyant oceanic lithosphere incapable of 910 participating in subduction (Bostock, 1998) or through the amalgamation of arc material 911 (Jordan,1978). Both of these processes are dominated by lateral motion and large- 
912 scale deformation (Figures 7C \& D). Indeed, a puzzling component of this hypothesis is

913 the capacity for high-deforming processes to form stable, long-lived features.

914

915 Cooper et al. (2006) demonstrated the feasibility of forming stable lithosphere either

916 through thrust stacking of buoyant oceanic lithosphere or accretion/accumulation of arc

917 lithosphere. The authors used a combination of numerical simulations and theoretical

918 scaling relationships to map out the parameters that allowed for thickening of

919 lithospheric material over a downwelling in a convection cell. Two scenarios arose: the

920 lithospheric material thickening via localized deformation (akin to thrust stacking) or

921 through viscous deformation (more indicative of arc amalgamation) (Cooper et al.,

922 2006). Both required the initial material to be buoyant so as to resist entrainment into

923 the mantle downwelling. Indeed, this limitation is what drove Jordan (1978) and Bostock

924 (1998) to suggest either arc lithosphere or buoyant oceanic lithosphere as the thickened

925 proto-cratonic lithosphere. The material must be sufficiently buoyant to explain the

926 observed compositional buoyancy, but also remain neutrally (or positively) buoyant

927 (Jordan, 1978) both at the time of formation and subsequent evolution in a cooling

928 Earth.

929

930 The differing styles of thickening (thrust stacking vs amalgamation) observed within the

931 simulations depended on the rheological properties of lithosphere (Cooper et al., 2006).

932 Deformation occurred through a localized manner along shear bands in simulations with

933 stronger, more viscous lithospheric material whereas those with weaker, less viscous

934 material deformed in a distributed fashion with no distinguishable shearing (Cooper et 
935 al., 2006). Thus, the manner of lithosphere thickening invoked to explain craton

936 formation is dependent on the rheology of the proto-cratonic lithosphere. Gray et al.

937 (2010) also demonstrated the controls that rheology plays on simulations of continental

938 collision, though this study focused more on the crustal influence on deformation rather

939 than the entire lithosphere. Regardless of the differing rheological framework, both

940 styles of thickening produced thick, stable features within the simulations wherein

941 deformation within the lithosphere ceased, or significantly decreased (small-scale

942 dripping occurred along the base of the viscously thickened lithosphere, but large-scale

943 deformation ended), even though convection continued (Cooper et al., 2006).

945 The act of the thickening itself drove the transition to stability within these simulations.

946 As the lithospheric thickness increased, the effective yield stress increased (necessary

947 to cease localized shearing) as well as the integrated buoyancy (suppressing

948 entrainment, delamination or dripping) (Cooper et al., 2006). Both of these conditions

949 depend not only on the material properties of the lithosphere, but also on the dynamic

950 setting of the convecting mantle. In other words, to turn off yielding within the

951 lithosphere the effective yield strength must be higher than the convective stresses. To

952 resist entrainment, the integrated buoyancy must exceed the negative thermal

953 buoyancy of the mantle downwelling. Thus to achieve longevity, the lithosphere must

954 exceed a critical thickness to ensure stability not only in the past dynamic setting when

955 formed (e.g., Lenardic \& Moresi, 1999), but also sufficiently thick to offset the increase

956 in convective stresses and negative thermal buoyancy of the cooling, thermal boundary

957 layer (Cooper et al., 2006). The progressive cooling of the cratonic lithosphere itself will 
958 contribute to an additional strengthening due to the temperature-dependent rheology.

959 This is a necessity for the more distributed thickening regime which does allow for small

960 drips to form at the base of the lithosphere. Cooling of the temperature-dependent

961 lithosphere will help suppress potential thinning from these drips (Molnar et al., 1998).

962 The localized thickening (or thrust stacking) behavior does not experience these drips

963 due to the high viscosity required for the behavior to develop, but stability through this

964 process does assume healing of shear zones once the stresses to promote yielding are

965 no longer present (Cooper et al., 2006).

966

967 Much like the Rey et al. (2014) continental collapse model, all of these models requires 968 assuming a priori an initial lithospheric material that is buoyant from the onset. This is

969 where these lines of models run into difficulty, in particular, the thrust stacking of

970 buoyant oceanic lithosphere. The buoyancy in the buoyant oceanic lithosphere is

971 supplied by thick basaltic crust (a consequence of greater melt production driven by

972 higher mantle temperatures in the past). This buoyancy is most likely not a permanent

973 condition as basalt transitions to the denser eclogite under pressure. In present day

974 subduction zones, the density change associated with this metamorphic reaction helps

975 drive the downward motion of the subducting oceanic lithosphere (Peacock, 1993). If

976 cratonic lithosphere is formed by the progressive thickening of buoyant oceanic

977 lithosphere, buoyancy would be lost if a significant portion of the basaltic crust

978 transforms to eclogite once at depth. Arc lithosphere is also problematic as mafic

979 cumulates are the complementary residue to the more felsic or intermediate buoyant

980 crust (e.g., Rudnick, 1995). Thus, it is unclear that the buoyancy required to thicken 
981 either material through lateral motion can be achieved without preferentially removing

982 the dense material either during thickening (Kay \& Kay, 1993; Krystopowicz \& Currie,

983 2013; Wood, 2014) or post formation through the overturn of the entire thickened

984 lithosphere (Percival \& Pysklywec, 2007).

985

986 Regardless whether thrust stacking of buoyant oceanic lithosphere, arc accumulation or

987 continental collision, the thickening of the lithosphere as driven by lateral motion

988 introduces complex structure at depth. Cooper \& Miller (2014) expanded upon the

989 earlier models in a manner that highlighted structures that would arise from such large-

990 scale deformation. The authors show that if deformation occurred in a more distributed

991 manner, horizontal planar features would be produced, but if deformation localized into

992 shear zones, dipping structures developed in the lithospheric interior (Cooper \& Miller,

993 2014) - see also Figure 8C). Similar studies (e.g., Gray et al., 2010) also show the

994 dependency of lithospheric structure on deformation style. This provides an explanation

995 for the varied nature of lithospheric structure in differing cratons regions; thickening

996 driven by lateral motion can produce a range of features depending on the rheological

997 conditions. This suggests that some form of lateral accretion was likely at work during

998 the formation of cratonic lithosphere given the observed complexity within the deep

999 structure, though there are still many unanswered questions about the origin of the

1000 material that has been thickened and whether the thickening process was driven by true

1001 plate tectonic behavior or by the transition toward modern day processes. 


\section{Comparison with Modern Analogues}

1004

1005 While geodynamic models clearly suggest a mobile-lid, laterally-driven model of 1006 thickening of the Archean lithosphere was responsible for the widely observed, dipping 1007 structures, the extent to which this process is comparable to modern accretion is still an 1008 open question. It is useful, then, to examine what we know about the structural

1009 aftermath of the lateral assembly of continental lithosphere in the modern Earth.

\section{$1010 \quad 5.1$ Accretion dynamics}

1011 The nature of plate tectonics is to draw any material on an oceanic plate inexorably into 1012 collision with a subduction zone. Whether such material is recycled into the mantle or 1013 accreted onto the overriding plate is determined by dynamic considerations related to 1014 the relative buoyancy and strength of the ingested material, the subducting slab and 1015 whether the overriding plate is sufficiently deformable to accommodate the incoming 1016 material.

1018 For example, two-dimensional models of oceanic plateaus colliding with subduction 1019 zones by Arrial \& Billen (2013) show that eclogitization of the plateau crust inhibits 1020 accretion by increasing slab negative buoyancy with the potential for underplating of the 1021 plateau after slab break-off. Tetreault \& Buiter (2012) argue that the strength of the 1022 incoming material is important in allowing a buoyant anomaly to be sliced at the base 1023 from the down-going plate and emplaced on the over-riding plate. van Hunen \& Allen 1024 (2011) show how congestion of the subduction zone by a strongly-buoyant continental 1025 ribbon can lead to slab break-off and stalled convergence. 
1027 In a two dimensional cross-section, the structural signatures of these forms of accretion 1028 are integrated in a study by Vogt \& Gerya (2014) who propose three distinct modes of 1029 accretion. (1) Frontal accretion in which the terrane butts up against the overriding plate, 1030 and remains vertically coherent with the underlying oceanic lithosphere after slab 1031 breakoff. (2) Basal accretion in which the plateau is significantly underthrust below the 1032 overriding plate, is sheared from the oceanic, downgoing plate, and stranded after 1033 subduction restarts. This produces a dipping structure akin to that in Figure 8C. (3) An 1034 underplating mode in which the buoyant plateau rebounds after partial subduction and 1035 is emplaced vertically into the lithosphere behind the arc. These modes are described in 1036 terms of plateau collision but can be generalized to the subduction of any buoyant 1037 anomaly carried by the sea-floor.

1038

1039 Some accretionary orogenic belts remain active for hundreds of millions of years during 1040 which time they accumulate a collage of terranes including arcs, back-arc, and micro1041 continents or continental ribbons (Wilhem et al., 2012). The age of the subducting plate 1042 will vary in time and along the strike of the margin, each of the multiple incoming 1043 terranes will have different physical characteristics that influence the style of accretion, 1044 and the nature of the overriding plate is itself evolving. Examples of Phanerozoic and 1045 Mesozoic accretionary orogens include the Altaïds in central Asia (Wilhem et al., 2012), 1046 Tasmanides along the eastern margin of Gondwana (Glen, 2005) and the North 1047 American Cordillera (Johnston, 2001). 
1049 The along-strike variability nature of the margin in North America (see map from 1050 Hildebrand (2013) for an example) reminds us that modeling in cross section is a 1051 significant simplification of the true Earth. Three-dimensional dynamic models that 1052 include laterally varying structures in both the overriding and incoming plate are 1053 essential in trying to understand these complex structure observed on Earth.

1054

1055 Moresi et al. (2014) and Betts et al. (2015) developed 3D models of the accretion of 1056 plateaus, oceanic large igneous provinces, and continental ribbons. Their models trace 1057 the entire lifecycle of an accreting terrane from collision, to underthrusting/suturing, 1058 indentation into the overriding plate, and finally to the point where subduction re-starts 1059 with the terrane becoming part of the upper plate. A representative of such a model is 1060 illustrated in Figure 8 (A, B \& D) and shows snapshots of the accretion of a small (125

$1061 \mathrm{~km}$ radius, shown in cross section), medium (250 km) and large (500 km radius)

1062 buoyant anomaly representing an oceanic plateau (Moresi \& Willis, 2015; Betts et al., 1063 2015). In all of the simulations, the plateau dimension is a small fraction of the overall 1064 length of the convergent margin allowing the subduction system to evolve smoothly 1065 through the accretion event and recover.

1067 The smallest plateau ( $125 \mathrm{~km}$ radius - shown with orange markers) is partly eroded from 1068 beneath and the remainder is accreted at the edge of the continental margin (Figure $8 \mathrm{~A}$ $1069 \& \mathrm{D})$. The suture is vertical near the surface, then transitions to a dipping feature at 1070 depth. A small slab window forms as the plateau is stripped from the oceanic 1071 lithosphere. The dipping section of the suture is stripped away once subduction restarts 
1072 (in Figure 8D this occurs between 65 and $70 \mathrm{Myr}$ ). For both the larger plateaus, the

1073 structure of the suture is similar, but the buoyant material indents significantly inboard

1074 into the margin which undergoes shortening close to the indentor, lateral escape, and

1075 modest extension in the lithosphere adjacent to the collision forming an orocline in the

1076 overriding plate. The restarting of subduction behind the indentor is through a buckling

1077 of the oceanic lithosphere driven by the adjacent, intact slab and this buckling overturns

1078 the rear of the accreted terrane and entrains a small section of the oceanic crust. The

1079 original suture is inboard of the new slab and remains undisturbed in this case.

1080

1081

(A)

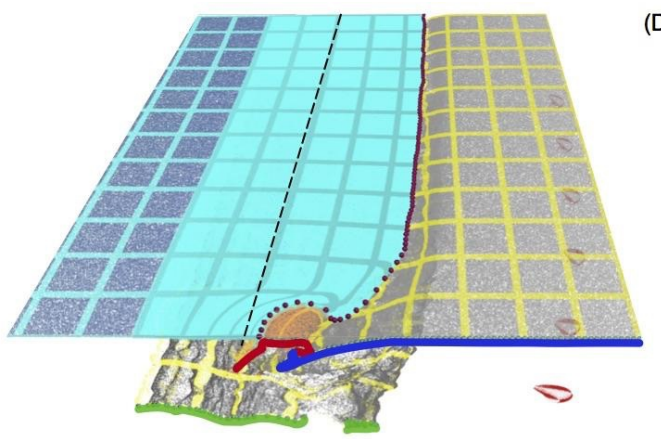

(B)

(C)

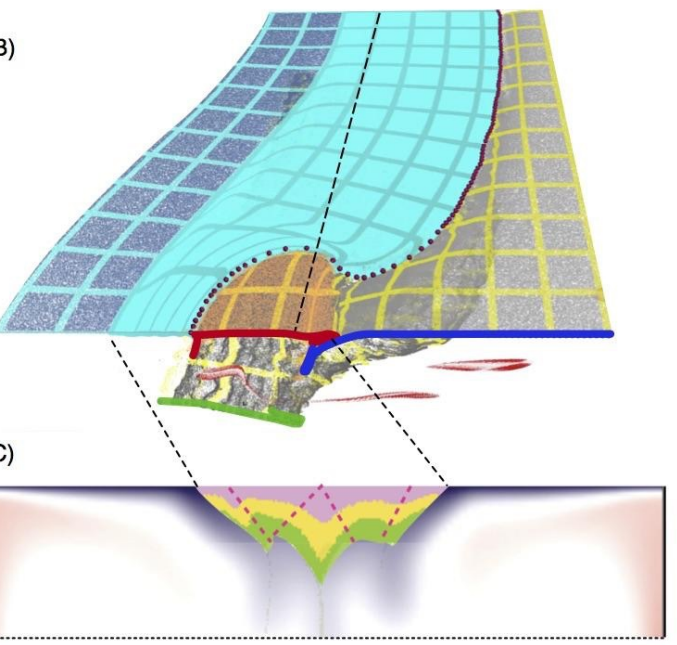

(D)
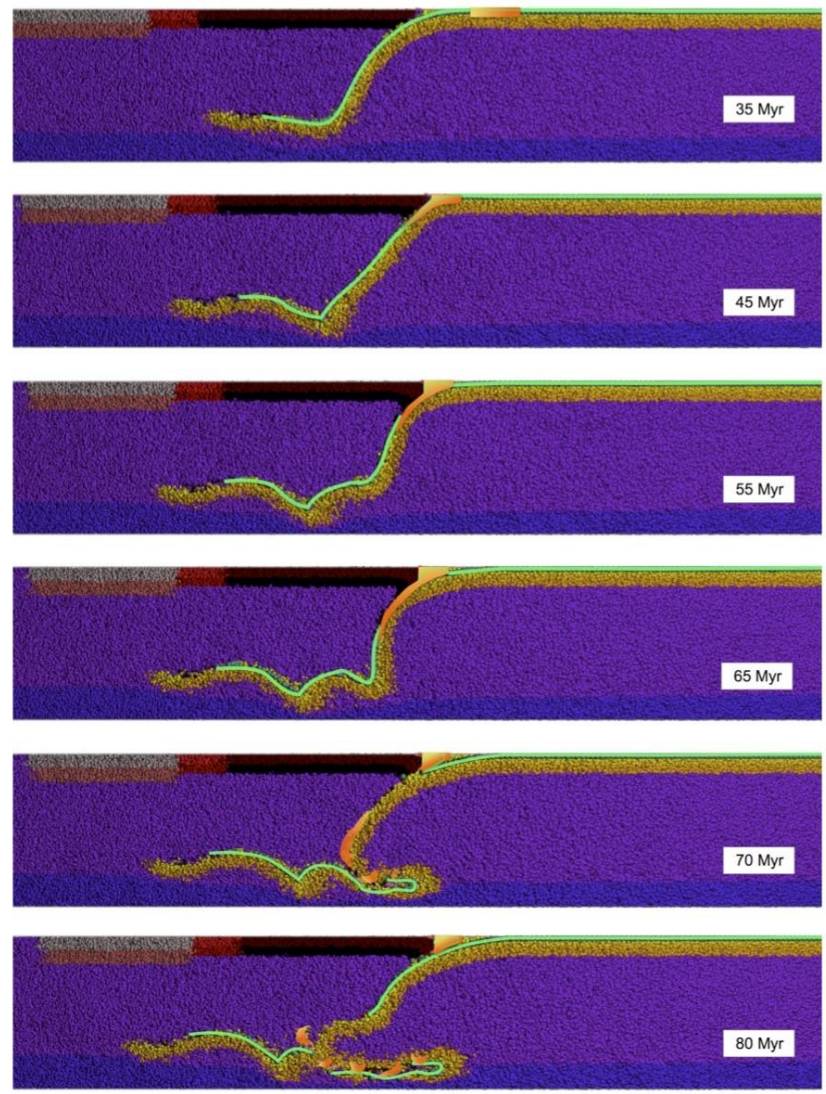
Figure 8. Three dimensional models of accretion of (A) a $250 \mathrm{~km}$ and (B) a $500 \mathrm{~km}$ radius oceanic plateau (shown with orange markers) into a deformable margin (snapshots of movies from Moresi \& Willis (2015) showing only their marker surfaces). The oceanic plate is grey with a yellow strain-marker grid. The continental crust is dark blue with a light grid. Transitional crust is cyan with a grey grid. The indenting plateau is orange. The plate boundary is a purple dotted line. The dark, dashed line indicates the position of the trench at the onset of collision. The colored lines indicate the cross-sectional view of the pre-collision lower-plate lithosphere (green), the plateau (red), and the postcollision lower-plate lithosphere (blue). (C) shows the correspondence between the high-resolution 2D, thermalmechanical models of Cooper \& Miller (2014) and the compositional-mechanical 3D models. (D) is a cross section 1092 through the collision of a $125 \mathrm{~km}$ radius plateau showing all material elements (Betts et al., 2015) and illustrating a geometry similar to that of the Yakutat subduction and accretion.

The congestion of the subduction zone drives horizontal compression of the margin lithosphere ahead of the indentor/plateau similar to the geometry modeled by Cooper \& Miller (2014) as shown in Figure 8C, and their analysis of the conditions for localized versus distributed deformation can be applied in the plane perpendicular to the collision.

1099 However, as the indentor/plateau also produces lateral extrusion of the lithosphere, 1100 there is significant strike-slip deformation which, when localization occurs, forms the 1101 classical escape-tectonics pattern of faulting (e.g., Tapponnier et al., 1982 and shown in

1102 Moresi et al., 2014). This has the potential to greatly complicate the analysis of a long1103 lived accretionary margin with multiple cycles of interpenetrating collision. 
1110 closure (Foster \& Gray, 2000); and 2) southern Alaska: the ongoing accretion of the

1111 Yakutat block in the eastern end of the Aleutian/Alaskan subduction zone (Figure 10).

1113 The structural evolution of the accretion of the Selwyn block, and the associated

1114 Lachlan fold belt and orocline system in Australia has been extensively documented by

1115 Cayley (2011) and coworkers, and supports the dynamic framework for accretion

1116 outlined above. Recent observations of seismic anisotropy and interpretation of

1117 magnetic fabric, together with regional tomographic imaging further support the causal

1118 connection between the indentation of the Selwyn block, the associated fold belt, and

1119 the surrounding orocline (Rawlinson et al., 2014; Pilia et al., 2015).

1121 Figure 9 shows a simplified geological map of the accreted Selwyn block (the northern

1122 tip of the VanDieland microcontinent as outlined in red in Figure 9C) showing the

1123 Lachlan orocline which is thought to be composed of the dissected remnants of the pre-

1124 accretion margin and arc. The curved, red arrow shows the approximate sense of

1125 motion of the tectonic escape during collision. Note the later (Devonian) arc that

1126 indicates where the subduction zone re-established itself post-accretion. The seismic

1127 evidence for the oroclinal fabric (Figure 9B) and the indented block (Figure 9C) is taken

1128 from Rawlinson et al. (2014) and Pilia et al. (2015), respectively. 


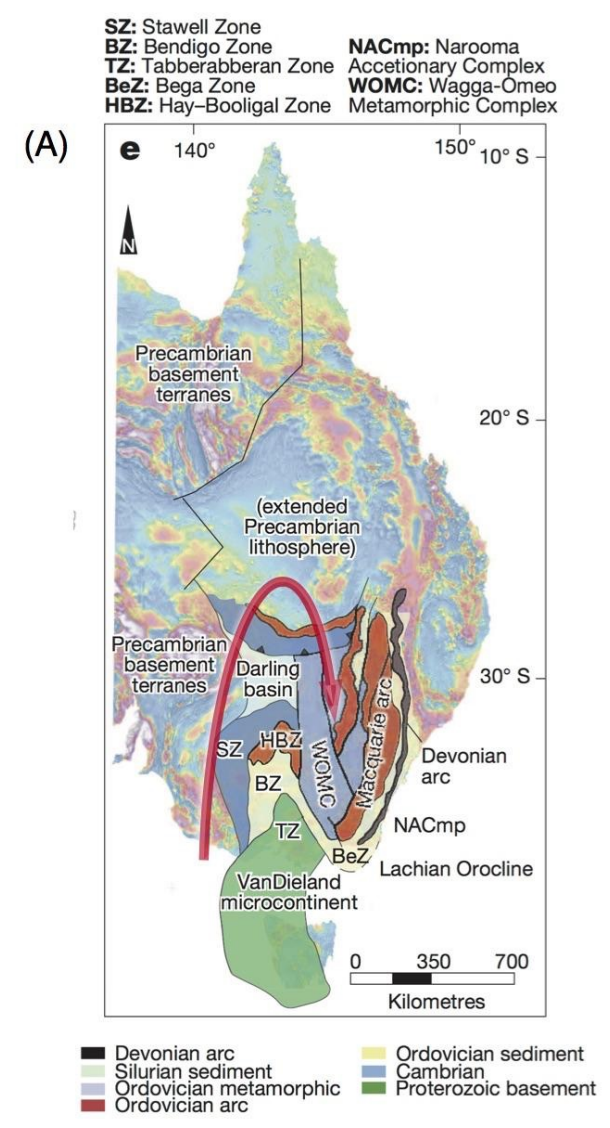

(B)

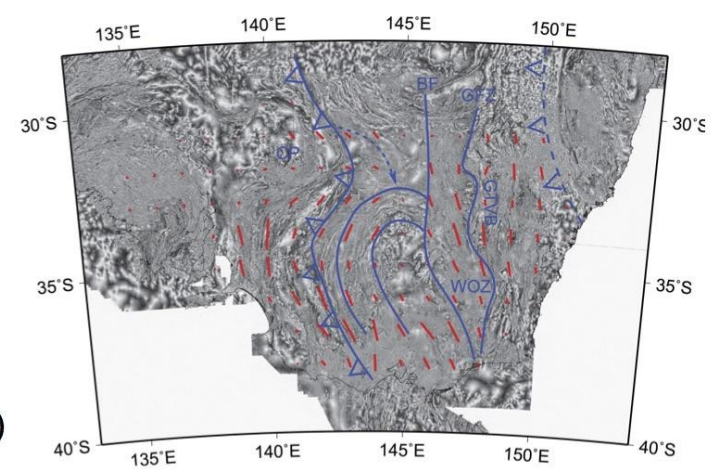

(C)

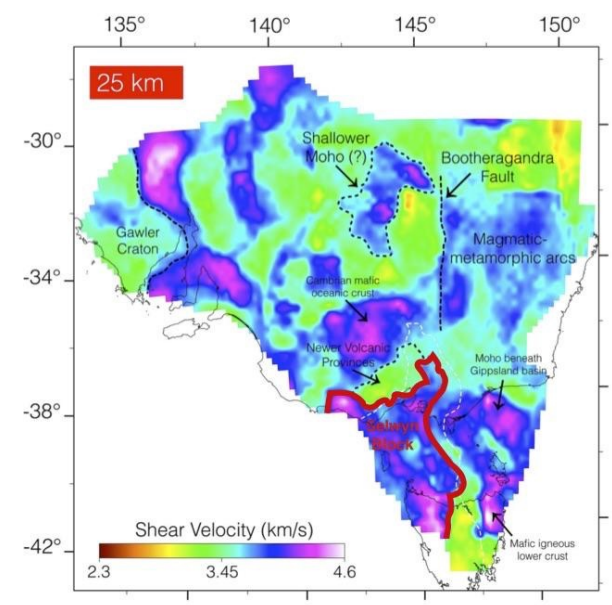

1131 Figure 9. (A) is a simplified regional tectonic map of the southern and central Tasmanides superimposed on a

1132 magnetic intensity map of eastern Australia (Moresi et al., 2014). The curved red arrow shows the sense of overall

1133 motion predicted by numerical models and inferred from the geological and geophysical interpretation of Cayley

1134 (2011). (B) the orientation of the seismic fast direction (dark red vectors) superimposed on magnetic data with an

1135 interpretation of the inferred fabric shown in blue (Rawlinson et al., 2014). (C) Seismic shear-wave velocity

1136 anomalies at $25 \mathrm{~km}$ from the regional tomographic model of Pilia et al. (2015) with their outline of the seismic

1137 signature of the Selwyn block at depth (red contour).

1139 A modern example of collision of a buoyant plateau at a continental convergent margin is at the 1140 eastern end of the Aleutian subduction zone. This collision is the most recent in a series

1141 of accreted terranes that have formed the northern Cordillera (Figures 8 and 11C). This

1142 collision results in a section of flat-slab subduction due to the underthrusting of the 
1143 Yakutat Plateau (Eberhart-Phillips et al., 2006). The Yakutat terrane continues to

1144 actively collide with the margin, (Figure 10E: Freymueller et al., 2008), bisect the

1145 Chugach terrane and results in accentuating the curvature of the Alaskan orocline.

1146 Previous sutures have been reactivated in strike-slip deformation (Figure 10 C\&D) and

1147 now form part of the orocline and associated lateral escape (Glen, 2004).

(A)

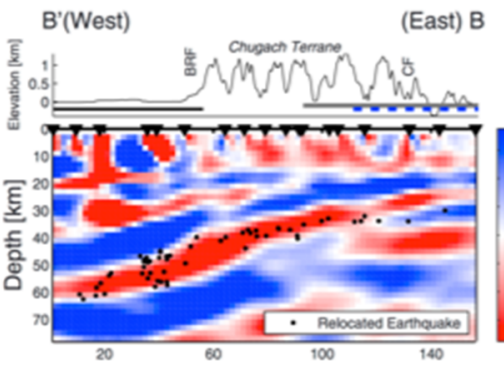

(B)

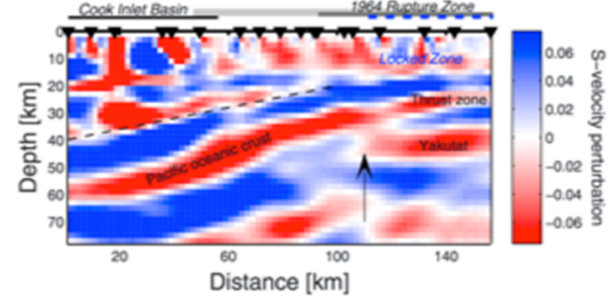

(C)

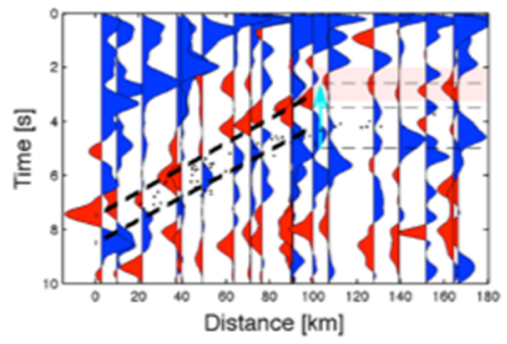

(D)

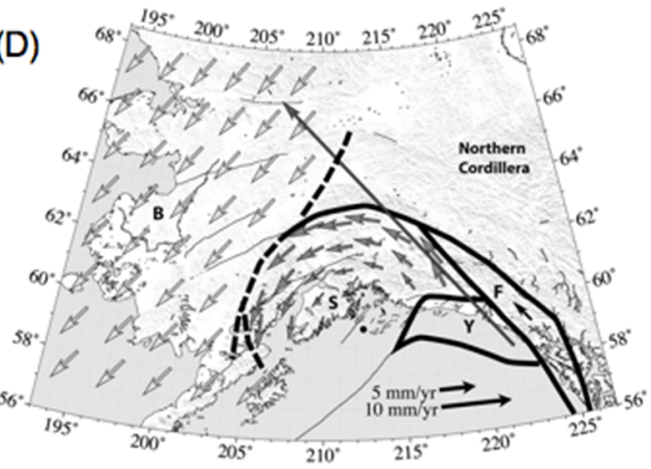




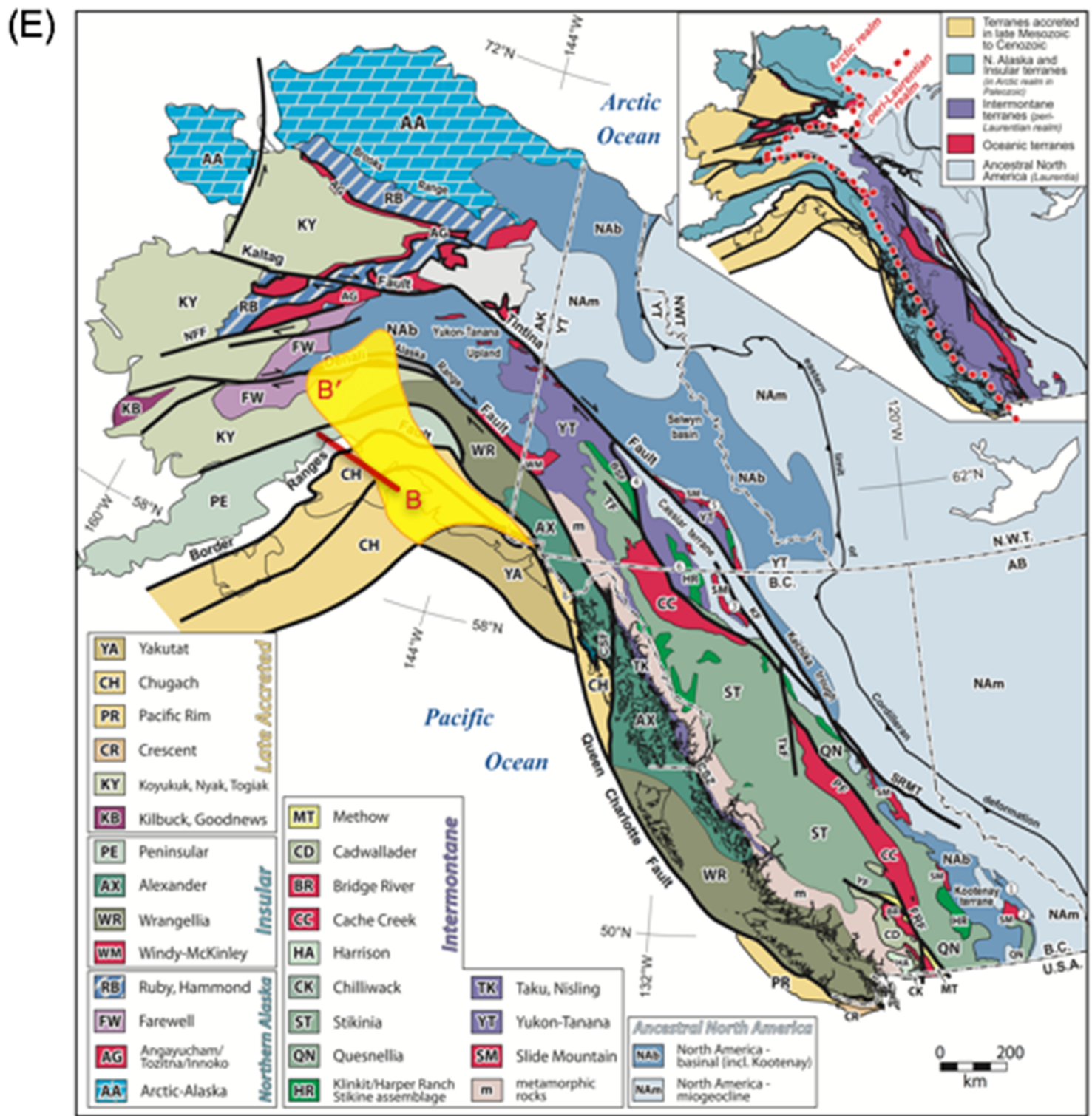

1170 Figure 10. (A-C) Seismic discontinuity imaging from (Kim et al., 2014) in southern Alaska showing a profile (B-B')

1171 that cuts obliquely across the subducting portion of the Yakutat terrane. The interpreted seismic images show the

1172 low-velocity Pacific oceanic crust and the westernmost extent of the Yakutat terrane being subducted beneath the

1173 Chugach terrane on the North American plate. The arrows indicate the position of the Yakutat in both the GRT based

1174 images (see Kim et al., (2014) for details) and the stacked P receiver functions. (D) shows a simplified tectonic map

1175 of Alaska (Colpron et al., 2007) that highlights the long history of accretion, the present day orocline, and the

1176 dissection of the margin by the incoming Yakutat block. The yellow patch indicates the approximate extent of the

1177 subducted Yakutat crust from (Eberhart-Phillips et al., 2006) and the red line is the location of the profile (B-B') in the 
left hand column (A-C). (Eberhart-Phillips et al., 2006). (E) Freymueller et al. (2008) block rotation model for the

1181 P receiver functions results (Figure 10A-C) concentrated across the southern half of 1182 central Alaska effectively image the Yakutat Plateau offshore (Worthington et al., 2012;

1183 Christeson et al., 2013), through the forearc (including the Yakutat-Pacific boundary) 1184 (Kim et al., 2014), and northward below the Alaska Range and major strike-slip Denali

1185 Fault (Ferris et al., 2003; Rondenay et al., 2010; Brennan et al., 2011) illustrating sharp 1186 structures at quite fine resolution (a few kilometers).

1188 As the models show in Figure 8, the slab can flatten and/or break off in response to 1189 congestion by anomalously buoyant crust. This will result in trench advance in this 1190 section. The majority of the subduction zone is not congested and will continue to 1191 subduct although with an enhanced tendency to retreat (a geometrical requirement to 1192 accommodate the escape of material from the collision). The Yakutat collision (Figure 1193 10) appears to follow these general observations and has a similar morphology to the 1194 Lachlan orocline (Figure 9). Of particular note is that, in both cases, there has been 1195 considerable lateral movement of the previously-accreted terranes through re-activation 1196 of the original suture zones. If the Yakutat collision is typical of an accreting terrane, the 1197 present shallow-dipping, underthrust section associated with flat-slab subduction, would 1198 be highly modified and, presumably, detached from the colliding section of the terrane 1199 by strike-slip reactivation of the shallow suture (Denali Fault). 


\section{6. Conclusions and Suggestions for Future Work}

There are some commonalities between modern accretion processes, the structures

1204 they produce and the structures preserved within older, cratonic lithosphere (Figure 8).

1205 In particular, modern accretion introduces features (Figure 10) reminiscent of the

1206 dipping structures observed in cratonic regions. It is interesting to note that a significant

1207 portion of deformation in modern accretion settings is accommodated by strike-slip

1208 motion which may not be captured in deeper lithospheric structure. Tracking anisotropy

1209 patterns, however, seems to be a way to locate the signature of accretion once the

1210 orogeny is complete. This approach may also be applicable for mapping out fabric

1211 associated with ancient orogenic events (e.g., Wirth \& Long, 2014; Pilia et al., 2015). In

1212 addition, while vertical tectonics are still in operation on modern Earth (e.g., lithospheric

1213 drips in the western United States, see Zandt et al., 2004 and West et al., 2009), it is

1214 unclear as to whether these events are part of the accretionary process or a

1215 consequence of other controls on continental deformation. If the latter, these more

1216 modern events could also serve as modern analogues to test against the hypotheses of

1217 craton formation that invoke vertical tectonics.

1219 Regardless, continued mapping of a more detailed view of the structure within

1220 continental lithosphere can help continue to determine the similarities between modern

1221 and ancient accretion as well as provide valuable information about the composition and

1222 rheology of cratonic lithosphere. Within models of lithospheric deformation, the

1223 structure produced is dependent on its material properties as well as the dynamic

1224 setting (Cooper et al., 2006; Gray et al., 2010; Cooper \& Miller, 2014). Dipping 
1225 structures are more indicative of localized deformation occurring in shear zones in

1226 strong lithosphere. Planar features result from distributed deformation in weaker

1227 lithosphere. Planar features could also be produced by melting events as described in

1228 the dynamics section. Placing the structural observations within the geodynamic

1229 context can help winnow the candidates for proto-cratonic lithosphere (i.e., buoyant

1230 oceanic lithosphere, arc lithosphere or potentially another unexplored option).

1232 The observational similarities between modern and ancient lithosphere suggests that

1233 lateral accretion of lithospheric material played a role in craton formation especially

1234 when coupled with geodynamic models that demonstrate the processes that produce

1235 similar structures. However, whether this lateral motion was a consequence of fully

1236 developed plate tectonic behavior or of a potentially, unstable transition period between

1237 regimes still remains to be resolved. The transition from whichever early tectonic

1238 regime in operation in the early Earth to plate tectonics was most likely not

1239 instantaneous and probably tumultuous. Understanding this transition could help

1240 provide a solution for the observed differences between modern and ancient accretion.

1241 We do note that most of the geodynamic simulations for craton formation and/or

1242 continental collision during the early Earth are limited to the two-dimensional geometric

1243 framework. Further work would be advanced by exploring three-dimensional studies.

1245 While the more complex structure of continental lithosphere does share similarities with

1246 modern accretion, there are still many unanswered questions, setting the stage for

1247 exciting avenues of future work. For example, modern accretion does not seem to 
1248 produce as thick a lithosphere; why not? Is making thick lithosphere limited to the 1249 Archean and Proterozoic? If the proto-cratonic lithosphere is either buoyant oceanic or

1250 arc lithosphere, what are the steps of removing dense material while still maintaining the 1251 stability and thickness associated with the present day state of cratonic lithosphere?

1252 What would accretion in the early Earth look like if driven by weaker subduction zones

1253 as proposed by van Hunen \& van den Berg (2008) or if it occurred as a consequence of 1254 the breakdown of the heat pipe regime (Moore \& Webb, 2013)?

1255

1256 Another intriguing question is the ability for the lithosphere to retain or lose evidence of

1257 deformation. Cratonic lithosphere appears to have a long memory of past deformation.

1258 Is this dependent on unique material properties or the lack of exposure to additional

1259 deformation? Interestingly, younger lithosphere, at times, also retains evidence of past

1260 events. Recently, McKenzie et al. (2015) observed that when global lithospheric

1261 thickness maps were reconstructed to the configuration of Pangea that the thicker

1262 regions aligned in a continuous manner. This suggests that today's regions of thicker

1263 lithosphere (minus cratonic regions) are holding on to the evidence of the last

1264 continental collision. However, perplexingly, most of the observed mid-lithospheric

1265 discontinuities (MLDs) are in cratonic regions. Is this because younger lithosphere does

1266 not retain them as easily or because the deformation is accommodated differently?

1267 Furthermore, there is significant evidence that suture zones and other features are often

1268 reactivated in more modern settings (Holdsworth et al., 2001). Yet, if some of the

1269 observed structures in cratonic lithosphere are suture zones, what makes them resistant

1270 to reactivation? Does this indicate healing or lack of sufficient and/or appropriately 
1271 oriented stresses? And does this connect to other pressing questions about craton

1272 stability such as why have some cratonic regions have deformed and been "destroyed"

1273 (Gao et al., 2004; Abdelsalam et al., 2011; Guo et al., 2016) while other seems to

1274 deflect deformation to their exteriors (e.g., Koptev, et al, 2015)?

1275

1276 We should note that there are other interpretations for the source of the mid-lithospheric 1277 discontinuities including phase transitions (Selway et al., 2015) or partial melting (Thybo

1278 \& Perchuc, 1997) indicative of late stage (or near present day) modification to the 1279 continental lithosphere or grain boundary sliding (Selway et al., 2015; Karato et al., 1280 2015). Regional studies, as proposed below, would help further delineate between 1281 these differing explanations for the mid-lithospheric discontinuities. Even if the 1282 presence and nature of the mid-lithospheric discontinuities prove to be less than 1283 relevant to the tectonic evolution story, there are plenty of other techniques, several of 1284 which mentioned, that can be used to investigate the deep structure of the continental 1285 lithosphere.

1287 We can start addressing many of these unanswered and pressing questions with 1288 additional focused, regional studies of both cratonic and accretion settings that couple 1289 seismic imaging, gravity, and magnetotelluric studies. Similar approaches such as

1290 (Jones et al., 2002; Afonso et al., 2016) can help further identify and detail

1291 characteristics of modern and ancient deformation. Focus should also be made to 1292 chronicle the differences between cratonic lithosphere from different regions (both 1293 geochemically and seismologically). Too often it is tempting to group regions based on 
1294 similarities into one conceptual model (such as in the cluster approach of Figure 1) and

1295 leave it at that. Perhaps, however, the differences in cratonic lithosphere may further

1296 highlight the processes at play during their formation and may suggest that not all

1297 cratonic lithosphere was formed in the same manner. Finally, we argue for continued

1298 collaboration between observationalists and geodynamicists. Some of the early

1299 mysteries of the Earth are trapped deep within the continents. We are moving closer to 1300 piecing the clues together, but it will certainly take a team effort.

\section{7. Acknowledgements}

1304 We thank Erika Rader for providing a list of MLD locations, Andrew Schaeffer for 1305 providing his tomography model. We also thank Norm Sleep, Lydia DiCaprio and one 1306 anonymous reviewer for their comments, encouragement and insight during the review 1307 process. The authors would like to acknowledge support from: NSF EAR-1112820

1308 (Cooper), NSF CAREER grant EAR-1054638 (Miller), and Australian Research Council 1309 Discovery Grants: DP130101946 and DP150102887 (Moresi). 


\section{References}

1311 Abdelsalam, M.G., Gao, S.S. \& Liegeois,J.-P., 2011. Upper mantle structure of the Saharan 1312 Metacraton. Journal of African Earth Sciences, 60(5), pp.328-336.

1313 Abt, D.L., Fischer, K.M., French, S.W., Ford, H.A., Yuan, H. \& Romanowicz, B., 2010. North 1314 American lithospheric discontinuity structure imaged by Ps and Sp receiver functions. 1315 Journal of Geophysical Research, 115(B9). Available at:

1316 http://dx.doi.org/10.1029/2009jb006914.

1317 Afonso, J.C., Moorkamp, M. \& Fullea, J., 2016. Imaging the Lithosphere and Upper Mantle. In 1318 Geophysical Monograph Series. pp. 191-218.

1319 Armann, M., Marina, A. \& Tackley, P.J., 2012. Simulating the thermochemical magmatic and 1320 tectonic evolution of Venus's mantle and lithosphere: Two-dimensional models. Journal of 1321 Geophysical Research: Planets, 117(E12). Available at:

1322 http://dx.doi.org/10.1029/2012je004231.

1323 Arrial, P.-A. \& Billen, M.I., 2013. Influence of geometry and eclogitization on oceanic plateau 1324 subduction. Earth and Planetary Science Letters, 363, pp.34-43.

1325 Artemieva, I.M., 2009. The continental lithosphere: Reconciling thermal, seismic, and petrologic 1326 data. Lithos, 109(1-2), pp.23-46.

1327 Aulbach, S., 2012. Craton nucleation and formation of thick lithospheric roots. Lithos, 149, 161328 30.

1329 BABEL Working Group, 1990. Evidence for early Proterozoic plate tectonics from seismic 1330 reflection profiles in the Baltic shield. Nature, 348(6296), pp.34-38. 
1331 Bao, X., Song, X., \& Li J., 2015. High-resolution lithospheric structure beneath Mainland China 1332 from ambient noise and earthquake surface-wave tomography. Earth and Planetary $1333 \quad$ Science Letters, 417, pp.132-141.

1334 Bao, X., Eaton, D.W. \& Guest, B., 2014. Plateau uplift in western Canada caused by lithospheric 1335 delamination along a craton edge. Nature Geoscience, 7(11), pp.830-833.

1336 Barrell, J., 1914. The Strength of the Earth's Crust. The Journal of Geology, 22(8), pp.729-741.

1337 Bastow, I.D., Thompson, D.A., Wookey, J., Kendall, J.-M., Helffrich, G., Synder, D.B., Eaton, 1338 D.W., \& Darbyshire, F., 2010. Precambrian plate tectonics: Seismic evidence from northern 1339 Hudson Bay, Canada. Geology, 39(1), pp.91-94.

1340 Becker, T.W. \& Boschi, L., 2002. A comparison of tomographic and geodynamic mantle models. Geochemistry, Geophysics, Geosystems, 3(1). Available at: http://dx.doi.org/10.1029/2001gc000168.

1343 Bédard, J.H., 2006. A catalytic delamination-driven model for coupled genesis of Archaean crust 1344 and sub-continental lithospheric mantle. Geochimica et cosmochimica acta, 70(5), pp.1188-1214.

1346 Bédard, J.H., Harris, L.B., \& Thurston, P.C., 2013. The hunting of the snArch, Evolving Early $1347 \quad$ Earth, 229, pp.20-48.

1348 Begg, G.C., Griffin, W.L., Natapov, L.M., O’Reilly, S.Y., Grand, S.P., O’Neill, C.J., Hronsky, 1349 M.A., Poudjom Djomani, Y., Swain, C.J., Deen, T., \& Bowden, P., 2009. The lithospheric 1350 architecture of Africa: Seismic tomography, mantle petrology, and tectonic evolution. $1351 \quad$ Geosphere, 5(1), pp.23-50.

1352 Betts, P.G., Giles, D., Lister, G., \& Frick, L., 2002. Evolution of the Australian lithosphere. 
1354 Betts, P.G., Moresi, L-.N., Miller, M.S., \& Willis, D., 2015. Geodynamics of oceanic plateau and 1355 plume head accretion and their role in Phanerozoic orogenic systems of China. Geoscience 1356 Frontiers, 6(1), pp.49-59.

1357 Betts, P.G., Giles, D. \& Aitken, A., 2011. Palaeoproterozoic accretion processes of Australia and comparisons with Laurentia. International Geology Review, 53(11-12), pp.1357-1376.

1359 Bostock, M.G., 1998. Mantle stratigraphy and evolution of the Slave province. Journal of 1360 Geophysical Research, [Solid Earth], 103(B9), pp.21183-21200.

1361 Brennan, P.R.K., Gilbert, H. \& Ridgway, K.D., 2011. Crustal structure across the central Alaska 1362 Range: Anatomy of a Mesozoic collisional zone. Geochemistry, Geophysics, Geosystems, 12(4). Available at: http://dx.doi.org/10.1029/2011gc003519.

Burke, K., Kevin, B. \& Kidd, W.S.F., 1978. Were Archean continental geothermal gradients 1365 much steeper than those of today? Nature, 272(5650), pp.240-241.

1366 Calò, M., Bodin, T. \& Romanowicz, B., 2016. Layered structure in the upper mantle across $1367 \quad$ North America from joint inversion of long and short period seismic data. Earth and $1368 \quad$ Planetary Science Letters, 449, pp.164-175.

1369 Cammarano, F., Tackley, P., \& Boschi, L., 2011. Seismic, petrological and geodynamical 1370 constraints on thermal and compositional structure of the upper mantle: global thermochemical models. Geophysical Journal International, 187(3), 1301-1318.

1372 Carlson, R. W., Boyd, F. R., Shirey, S. B., P. E. Janney, T. L. Grove, S. A. Bowring, M. D. 1373 Schmitz, J. C. Dann, D. R. Bell, J. J. Gurney, S. H. Richardson, M. Tredoux, A. H. Menzies, 1374 D. G. Pearson, R. J. Hart, A. H. Wilson, D. Moser, 2000. Continental Growth, Preservation, 

America, 10(2), pp.1-7.

1377 Carlson, R.W., Pearson, D.G. \& James, D.E., 2005. Physical, chemical, and chronological 1378 characteristics of continental mantle. Reviews of Geophysics , 43(1). Available at: 1379 http://dx.doi.org/10.1029/2004rg000156.

1380 Cawood, P.A., Kröner, A., Collins, W.J., Kusky, T.M., Mooney, W.D., \& Windley, B.F., 2009. 1381 Accretionary orogens through Earth history. Geological Society, London, Special $1382 \quad$ Publications, 318(1), pp.1-36.

1383 Cayley, R.A., 2011. Exotic crustal block accretion to the eastern Gondwanaland margin in the 1384

Chen, C.-W., Rondenay, S., Evans, R.L., \& Snyder, D.B., 2009. Geophysical detection of relict metasomatism from an Archean (approximately $3.5 \mathrm{Ga}$ ) subduction zone. Science,

1390 Christeson, G.L., Van Avendonk, H.J.A., Gulick, S.P.S., Reece, R.S., Pavlis, G. \& Pavlis, T.L., 326(5956), pp.1089-1091.

1393 Clowes, R.M., Cook, F., Hajnal, Z., Hall, J., Lewry, J., Lucas, S., and Wardle, R., 1999,

1394 Canada's LITHOPROBE Project (Collaborative, multidisciplinary geoscience research 1395 leads to new understanding of continental evolution): Episodes, v. 22, p. 3-20.

1397 Colpron, M., Nelson, J.L., \& Murphy, D.C., 2007. Northern Cordilleran terranes and their 
interactions through time. GSA today: a publication of the Geological Society of America, 17(4), p.4.

1400 Cook, F.A., van der Velden, A., Hall, K., \& Roberts, B.,1999. Frozen subduction in Canada's

$1401 \quad$ Northwest Territories: Lithoprobe deep lithospheric reflection profiling of the western

1402 Canadian Shield. Tectonics, 18(1), pp.1-24.

1403 Cooper, C.M., Lenardic, A., Levander, A., \& Moresi, L.-N., 2006. Creation and preservation of 1404 cratonic lithosphere: Seismic constraints and geodynamic models. In Geophysical $1405 \quad$ Monograph Series. pp. 75-88.

1406 Cooper, C.M. \& Conrad, C.P., 2009. Does the mantle control the maximum thickness of 1407 cratons? Lithosphere, 1(2), pp.67-72.

1408 Cooper, C.M. \& Miller, M.S., 2014. Craton formation: Internal structure inherited from closing of 1409 the early oceans. Lithosphere, 6(1), pp.35-42.

1410 Darbyshire, F.A. \& Eaton, D.W., 2010. The lithospheric root beneath Hudson Bay, Canada from 1411 Rayleigh wave dispersion: No clear seismological distinction between Archean and 1412 Proterozoic mantle. Lithos, 120(1-2), pp.144-159.

1413 Davies, G.F., 1992. On the emergence of plate tectonics. Geology, 20(11), p.963.

1414 Davies, G.F., 2006, Gravitational depletion of the early Earth's upper mantle and the viability of 1415 early plate tectonics, Earth and Planetary Science Letters, (243), pp.376-382.

1416 Dewey, J.F., 2007. The secular evolution of plate tectonics and the continental crust: An outline. 1417 In Geological Society of America Memoirs. pp. 1-7.

1418 Dueker, K.G. \& Sheehan, A.F., 1997. Mantle discontinuity structure from midpoint stacks of 1419 converted P to S waves across the Yellowstone hotspot track. Journal of Geophysical 
Research, [Solid Earth], 102(B4), pp.8313-8327.

1421 Eakins, C. \& Amante, B.W., 2009. Etopo1: 1 Arc-Minute Global Relief Model: Procedures, Data

1422 Sources and Analysis, National Geophysical Data Center, NOAA. Available at:

1423 http://books.google.com/books/about/Etopo1 1 Arc Minute Global Relief Model.html?hl=

1424 \&id=23MJywAACAAJ.

1425 Eaton, D. W., Darbyshire, F., Evans, R. L., Grütter, H., Jones, A. G., \& Yuan, X., 2009. The

1426 elusive lithosphere-asthenosphere boundary (LAB) beneath cratons. Lithos, 109(1), 1-22.

1427 Eaton, D.W. \& Perry, H.K.C., 2013. Ephemeral isopycnicity of cratonic mantle keels. Nature 1428 geoscience, 6(11), pp.967-970.

1429 Eberhart-Phillips, D., Christensen, D.H., Brocher, T.M., Hansen, R., Ruppert, N.A., Haeussler,

1430 P.H., \& Abers, G.A., 2006. Imaging the transition from Aleutian subduction to Yakutat

1431 collision in central Alaska, with local earthquakes and active source data. Journal of

1432 Geophysical Research, [Solid Earth], 111(B11). Available at:

1433 http://dx.doi.org/10.1029/2005jb004240.

1434 Farra, V. \& Vinnik, L., 2000. Upper mantle stratification by P and S receiver functions.

1435 Geophysical Journal International, 141(3), pp.699-712.

1436 Ferris, A., Abers, G.A., Christensen, D.H., \& Veenstra, E., 2003. High resolution image of the

1437 subducted Pacific (?) plate beneath central Alaska, 50-150 km depth. Earth and Planetary

$1438 \quad$ Science Letters, 214(3-4), pp.575-588.

1439 Fischer, K.M., 2015. Crust and Lithospheric Structure - Seismological Constraints on the $1440 \quad$ Lithosphere-Asthenosphere Boundary. In Treatise on Geophysics. pp. 587-612.

1441 Fischer, K.M., Ford, H.A., Abt., D.L., \& Rychert, C.A., 2010. The Lithosphere-Asthenosphere 
1443 Fishwick, S., 2010. Surface wave tomography: Imaging of the lithosphere-asthenosphere 1444 boundary beneath central and southern Africa? Lithos, 120(1-2), pp.63-73.

1445 Fishwick, S. \& Rawlinson, N., 2012. 3-D structure of the Australian lithosphere from evolving 1446 seismic datasets. Australian Journal of Earth Sciences, 59(6), pp.809-826.

1447 Ford, H.A., Fischer, K.M., Abt, D.L., Rychert, C.A., \& Elkins-Tanton, L.T., 2010. The 1448 lithosphere-asthenosphere boundary and cratonic lithospheric layering beneath Australia 1449 from Sp wave imaging. Earth and Planetary Science Letters, 300(3-4), pp.299-310.

1450 Foster, D.A. \& Gray, D.R., 2000. Evolution and Structure of the Lachlan Fold Belt (Orogen) of $1451 \quad$ Eastern Australia. Annual Review of Earth and Planetary Sciences, 28(1), pp.47-80.

1452 Fouch, M.J. \& Rondenay, S., 2006. Seismic anisotropy beneath stable continental interiors. $1453 \quad$ Physics of the Earth and Planetary Interiors, 158(2-4), pp.292-320.

1454 Francois, T., Burov, E., Meyer, B., \& Agard, P., 2013, Surface topography as key constraint on 1455 thermo-rheological structure of cratons, Tectonophysics, 602, pp. 106-123.

1456 Frederiksen, A.W. \& Bostock, M.G., 2000. Modelling teleseismic waves in dipping anisotropic 1457 structures. Geophysical Journal International, 141(2), pp.401-412.

1458 French, S., Lekic, V. \& Romanowicz, B., 2013. Waveform tomography reveals channeled flow at 1459 the base of the oceanic asthenosphere. Science, 342(6155), pp.227-230.

1460 Freymueller, J.T., Woodard, H., Cohen, S.,Cross, R., Elliot, J., Larsen, C., Hreinsdottir, S., \& 1461 Zweck, C., 2008. Active deformation processes in Alaska, based on 15 years of GPS 1462 measurements. In Geophysical Monograph Series. pp. 1-42. 
1463 Furnes, H., de Wit, M., Staudigel, H., Rosing, M., \& Muehlenbachs, K., 2007. A Vestige of 1464 Earth's Oldest Ophiolite. Science, 315(5819), pp.1704-1707.

1465 Gaherty, J.B. \& Jordan, T.H., 1995. Lehmann discontinuity as the base of an anisotropic layer 1466 beneath continents. Science, 268(5216), pp.1468-1471.

1467 Gao, S., Rudnick, R.L., Yuan, H.L., Liu, X.M., Liu, Y.S., Xu, W.L., Ayers, J., Wang, X.C., \& 1468 Wang, Q.H, 2004. Recycling lower continental crust in the North China craton. Nature, 1469 432(7019), pp.892-897.

1470 Gilbert, H., Susan, B. \& George, Z., 2006. Lithospheric and upper mantle structure of central 1471 Chile and Argentina. Geophysical Journal International, 165(1), pp.383-398.

1472 Glen, J.M.G., 2004. A kinematic model for the southern Alaska orocline based on regional fault 1473 1474 patterns. In Special Paper 383: Orogenic curvature: Integrating paleomagnetic and structural analyses. pp. 161-172.

1475 Glen, R.A., 2005. The Tasmanides of eastern Australia. Geological Society, London, Special 1476 Publications, 246(1), pp.23-96.

1477 Gray, R., Robert, G. \& Pysklywec, R.N., 2010. Geodynamic models of Archean continental 1478 collision and the formation of mantle lithosphere keels. Geophysical Research Letters, 1479 37(19). Available at: http://dx.doi.org/10.1029/2010gl043965.

1480 Griffin, W.L., O’Reilly, S.Y., Abe, N., Aulbach, S., Davies, R.M., Pearson, N.J., Doyle, B.J., \& 1481 Kivi, K., 2003. The origin and evolution of Archean lithospheric mantle. Precambrian $1482 \quad$ Research, 127(1-3), pp.19-41.

1483 Guo, Z., Afonso, J., Qashqai, M.T., Chen, \& J.Y.S., 2016. Thermochemical structure of the 1484 North China Craton from multi-observable probabilistic inversion: Extent and causes of 
cratonic lithosphere modification. Gondwana Research, 37, pp.252-265.

1486 Gutenberg, B., 1948. On the layer of relatively low wave velocity at a depth of about 80 kilometers, Bulletin of the Seismological Society of America, 38, pp. 121-148.

Gutscher, M.-A. Spakman, W., Bijwaard, H., \& Engdahl, E., 2000. Geodynamics of flat subduction: Seismicity and tomographic constraints from the Andean margin. Tectonics, 19(5), pp.814-833.

Hales, A.L., 1969. A seismic discontinuity in the lithosphere. Earth and Planetary Science Letters, 7(1), pp.44-46.

1494 Hammer, P.T.C., Clowes, R.M., Cook, F.A., van der Velden, A.J., \& Vasudevan, K., 2010. The 1495 Lithoprobe trans-continental lithospheric cross sections: imaging the internal structure of 1496 the North American continent, Lithoprobe Publication 1487. Canadian Journal of Earth 1497 Sciences, 47(5), pp.821-857.

1498 Hansen, S.M., Dueker, K. \& Schmandt, B., 2015. Thermal classification of lithospheric discontinuities beneath USArray. Earth and Planetary Science Letters, 431, pp.36-47.

1500 Hildebrand. R.S., 2013, Mesozoic assembly of the North American Cordillera: Geological $1501 \quad$ Society of America, Special Paper, 495, 162p.

1502 Holdsworth, R.E., Stewart, M., Imber, J., \& Strachan, R.A., 2001. The structure and rheological 1503 evolution of reactivated continental fault zones: a review and case study. Geological Society, London, Special Publications, 184(1), pp.115-137.

1505 Hopper, E., Ford, H.A., Fischer, K.M., Lekic, V. \& Fouch, M.J., 2014. The lithosphere1506 asthenosphere boundary and the tectonic and magmatic history of the northwestern United 1507 States. Earth and Planetary Science Letters, 402, pp.69-81. 
1508 Hopper, E. \& Fischer, K.M., 2015. The meaning of midlithospheric discontinuities: A case study 1509 in the northern U.S. craton. Geochemistry, Geophysics, Geosystems, 16(12), pp.4057$1510 \quad 4083$.

1511 Humphreys, E., 2009. Relation of flat subduction to magmatism and deformation in the western $1512 \quad$ United States. Geological Society of America Memoirs, 204(0), pp.85-98.

1513 Johnston, S.T., 2001. The Great Alaskan Terrane Wreck: reconciliation of paleomagnetic and 1514 geological data in the northern Cordillera. Earth and Planetary Science Letters, 193(3-4), $1515 \quad$ pp.259-272.

1516 Jones, A.G., Ferguson, I.J., Chave, A.D., Evans, R.L., \& McNeice, G.W., 2001. Electric 1517 lithosphere of the Slave craton. Geology, 29(5), p.423.

1518 Jones, A. G., Plomerova, J., Korja, T., Sodoudi, F., \& Spakman, W., 2010. Europe from the 1519 bottom up: a statistical examination of the central and northern European lithosphere1520 asthenosphere boundary from comparing seismological and electromagnetic observations. $1521 \quad$ Lithos, 120(1), 14-29.

1522 Jones, A.G., Snyder, D., Hanmer, S., Asudeh, I., White, D., Eaton, D., \& Clarke, G., 2002. 1523 Magnetotelluric and teleseismic study across the Snowbird Tectonic Zone, Canadian 1524 Shield: A Neoarchean mantle suture? Geophysical Research Letters, 29(17), pp.10-1-10_ 15254

1526 Jordan, T. H., 1975. The continental tectosphere, Reviews of Geophysics, 13(3), 1-12, 1527 doi:10.1029/RG013i003p00001.

1528 Jordan, T.H., 1978. Composition and development of the continental tectosphere. Nature, $1529 \quad$ 274(5671), pp.544-548. 
1530 Jordan, T. H.,1988. Structure and formation of the continental tectosphere. Journal of Petrology, $1531 \quad(1), 11-37$.

1532 Julià, J., Ammon, C.J., Herrmann, R.B., \& Correig, A.M., 2000. Joint inversion of receiver 1533 function and surface wave dispersion observations. Geophysical Journal International, 1534 143(1), pp.99-112.

1535 Karato, S.-I., Olugboji, T., \& Park, J., 2015. Mechanisms and geologic significance of the mid1536 lithosphere discontinuity in the continents. Nature Geoscience, 8(7), pp.509-514.

1537 Kay, R.W. \& Kay, S.M., 1993. Delamination and delamination magmatism. Tectonophysics, $1538 \quad$ 219(1-3), pp.177-189.

1539 Kerrich, R. \& Polat, A., 2006. Archean greenstone-tonalite duality: Thermochemical mantle 1540 convection models or plate tectonics in the early Earth global dynamics? Tectonophysics, $1541 \quad$ 415(1-4), pp.141-165.

1542 Kim, Y., Abers, G.A., Li, J., Christensen, D., Calkins, J., \& Rondenay, S., 2014. Alaska 1543 Megathrust 2: Imaging the megathrust zone and Yakutat/Pacific plate interface in the 1544 Alaska subduction zone. Journal of Geophysical Research, [Solid Earth], 119(3), pp.1924$1545 \quad 1941$

1546 Koptev, A., Calais, E., Burov, E., Leroy, S., \& Gerya, T., 2015. Dual continental rift systems 1547 generated by plume-lithosphere interaction. Nature Geoscience, 8(5), 388-392.

1548 Krystopowicz, N.J. \& Currie, C.A., 2013. Crustal eclogitization and lithosphere delamination in 1549 orogens. Earth and Planetary Science Letters, 361, pp.195-207.

1550 Kusky, T.M., Windley, B.F., Safonova, I., Wakita, K, Wakabayashi, J., Polat, A., \& Santos, M., 1551 2013. Recognition of ocean plate stratigraphy in accretionary orogens through Earth 
history: A record of 3.8 billion years of sea floor spreading, subduction, and accretion. Gondwana Research, 24(2), pp.501-547.

1554 Langston, C.A., 1977, Corvallis, Oregon, crustal and upper mantle receiver structure from 1555 teleseismic P and S waves: Bulletin of the Seismological Society of America, v. 67, p. 7131556724

1557 Laske, G., Masters, G. \& Ma, Z., Update on CRUST1. 0-A 1-degree global model of Earth's $1558 \quad$ crust. In Geophysical Research Abstracts. EGU General Assembly. European Geophysical $1559 \quad$ Union, pp. EGU2013-2658.

1560 Lee, C.-T.A., 2006. Geochemical/petrologic constraints on the origin of cratonic mantle. In 1561 Geophysical Monograph Series. pp. 89-114.

1562 Lee, C.-T.A., Luffi, P. \& Chin, E.J., 2011. Building and Destroying Continental Mantle. Annual 1563 Review of Earth and Planetary Sciences, 39(1), pp.59-90.

1564 Lehmann, I., 1961. S and the Structure of the Upper Mantle. Geophysical Journal International, 1565 4, pp.124-138.

1566 Lekic, V. \& Romanowicz, B., 2011. Tectonic regionalization without a priori information: A $1567 \quad$ cluster analysis of upper mantle tomography. Earth and Planetary Science Letters, 308(11568 2), pp.151-160.

1569 Lekić, V., Vedran, L. \& Fischer, K.M., 2014. Contrasting lithospheric signatures across the 1570 western United States revealed by Sp receiver functions. Earth and Planetary Science $1571 \quad$ Letters, 402, pp.90-98.

1572 Lenardic, A., \& Kaula, W. M., 1996. Near-surface thermal/chemical boundary layer convection 1573 at infinite Prandtl number: two-dimensional numerical experiments. Geophysical Journal 
1575 Lenardic, A., \& Moresi, L. N., 1999. Some thoughts on the stability of cratonic lithosphere:

1576 effects of buoyancy and viscosity. Journal of Geophysical Research [Solid Earth], 104(B6), $1577 \quad$ 12747-12758.

1578 Lenardic, A., Moresi, L. \& Mühlhaus, H., 2000. The role of mobile belts for the longevity of deep 1579 cratonic lithosphere: The Crumple Zone Model. Geophysical Research Letters, 27(8), $1580 \quad$ pp.1235-1238.

1581 Levander, A., Bezada, M.J., Niu, F., Humphreys, E.D., Palomeras, I., Thurner, S.M., Masy, J., 1582 Schmitz, M., Gallart, J., Carbonell, R., \& Miller, M.S., 2014. Subduction-driven recycling of 1583 continental margin lithosphere. Nature, 515(7526), pp.253-256.

1584 Levander, A. \& Miller, M.S., 2012. Evolutionary aspects of lithosphere discontinuity structure in 1585 1586 the western U.S. Geochemistry, Geophysics, Geosystems, 13(7). Available at: http://dx.doi.org/10.1029/2012gc004056.

1587 Levin, V. \& Park, J., 2000. Shear zones in the Proterozoic lithosphere of the Arabian Shield and 1588 the nature of the Hales discontinuity. Tectonophysics, 323(3-4), pp.131-148.

1589 Lin, F.-C., Ritzwoller, M.H., \& Snieder, R., 2009. Eikonal tomography: surface wave tomography 1590 by phase front tracking across a regional broad-band seismic array. Geophysical Journal $1591 \quad$ International, 177(3), pp.1091-1110.

1592 Long, M.D. \& Becker, T.W., 2010. Mantle dynamics and seismic anisotropy. Earth and $1593 \quad$ Planetary Science Letters, 297(3-4), pp.341-354.

1594 Lyell, C., 1837. Principles of Geology.

1595 Magnani, M.B., Miller, K.C., Levander, A., \& Karlstrom, K., 2004. The Yavapai-Mazatzal 
boundary: A long-lived tectonic element in the lithosphere of southwestern North America. Geological Society of America Bulletin, 116(9), p.1137.

McKenzie, D., Daly, M.C., \& Priestley, K., 2015. The lithospheric structure of Pangea. Geology, 43(9), pp.783-786.

Miller, M.S. \& Agostinetti, N.P., 2011. Erosion of the continental lithosphere at the cusps of the Calabrian arc: Evidence from S receiver functions analysis. Geophysical Research Letters, 38(23). Available at: http://dx.doi.org/10.1029/2011gl049455.

1603

1604

1605

1606

1607

1608

1609

1610

1611

1612

1613

1614

1615

1616

1617

Miller, M.S. \& Eaton, D.W., 2010. Formation of cratonic mantle keels by arc accretion: Evidence from S receiver functions. Geophysical Research Letters, 37(18). Available at: http://dx.doi.org/10.1029/2010gl044366.

Mohorovičić, A., 1910. Potres od 8.X 1909. Jahrbuch des meteorologischen observatoriums in Zagreb (Agram) für das Jahr 1909, 1-56. English translation, 1992. Earthquake of 1909 October 8. Geofizika, 9, 3-55.

Molnar, P., Houseman, G.A., \& Conrad, C.P., 1998. Rayleigh-Taylor instability and convective thinning of mechanically thickened lithosphere: effects of non-linear viscosity decreasing exponentially with depth and of horizontal shortening of the layer. Geophysical Journal International, 133(3), pp.568-584.

Moore, W., 2001. The Thermal State of lo. Icarus, 154(2), pp.548-550.

Moore, W.B. \& Webb, A.A.G., 2013. Heat-pipe Earth. Nature, 501(7468), pp.501-505.

Moresi, L.N., Betts, P.G., Miller, M.S., \& Cayley, R.A., 2014. Dynamics of continental accretion. Nature, 508(7495), pp.245-248. 
1618 Moresi, L. N. \& Solomatov, V.S., 1995. Numerical investigation of 2D convection with extremely 1619 large viscosity variations, Physics of Fluids, 7, 2154-2162.

1620 Moresi, L.N. \& Willis, D., 2015. Time Dependent Behaviour of Congested Subduction. Available 1621 at: http://www.elementsmagazine.org/supplements/e11_2_Moresi_Willis_Movies.html.

1622 Müller, R.D., Sdrolias, M., Gaina, C, \& Roest, W.R., 2008. Age, spreading rates, and spreading 1623 asymmetry of the world's ocean crust. Geochemistry, Geophysics, Geosystems, 9(4). 1624 Available at: http://dx.doi.org/10.1029/2007gc001743.

1625 Nokleberg, W.J., Parfenov, L.M., Monger, J.W.H., Norton, I.O., Khanchuk, A.I., Stone, D.B., 1626 Scotese, C.R., Scholl, D.W., \& Fujita, K., 2001. Phanerozoic Tectonic Evolution of the 1627 Circum-North Pacific, United States Geological Survey. Available at: 1628 http://pubs.usgs.gov/pp/2000/1626/.

1629 Nokleberg, W.J., Plafker, G. \& Wilson, F.H., Geology of south-central Alaska. In The Geology of $1630 \quad$ Alaska. pp. 311-366.

1631 O’Driscoll, L.J. \& Miller, M.S., 2015. Lithospheric discontinuity structure in Alaska, thickness 1632 variations determined by Sp receiver functions. Tectonics, 34(4), pp.694-714.

1633 Oldow, J.S., Bally, A.W., Ave Lallemant, H.G, \& Leeman, W.P., 1989. Phanerozoic evolution of 1634 the North American Cordillera; United States and Canada. In The Geology of North $1635 \quad$ America-An Overview. pp. 139-232.

1636 Olsson, S., Roberts, R.G., \& Böovarsson, R., 2007. Analysis of waves converted from S to P in 1637 the upper mantle beneath the Baltic Shield. Earth and Planetary Science Letters, 257(1-2), $1638 \quad$ pp.37-46.

1639 O’Neil, J., Carlson, R.W., Francis, D., \& Stevenson, R.K., 2008. Neodymium-142 Evidence for 
1641 O’Neill, C., Lenardic, A., Moresi, L.N., \& Lee., C.-T. A., 2007. Episodic Precambrian subduction. 1642 Earth and Planetary Science Letters, 262(3-4), pp.552-562.

1643 O'Neill, C. \& Debaille, V., 2014. The evolution of Hadean-Eoarchaean geodynamics. Earth and 1644 Planetary Science Letters, 406, pp.49-58.

1645 O’Reilly, S.Y., Griffin, W.L., Poudjom Djomani, Y.H. \& Morgan, P., 2001. Are Lithospheres $1646 \quad$ Forever? Tracking Changes in Subcontinental Lithospheric Mantle Through Time. GSA Today: a publication of the Geological Society of America, 11(4), p.4.

1648 Parker, E.H.,Jr., Hawman, R.B., Fischer, K.M., \& Wagner, L.S., 2015. Constraining lithologic $1649 \quad$ variability along the Alleghanian detachment in the southern Appalachians using passivesource seismology. Geology, 43(5), pp.431-434.

1651 Park, J. \& Levin, V., 2002. Seismic Anisotropy: Tracing Plate Dynamics in the Mantle. Science, 296(5567), pp.485-489.

1653 Parsons, B., Barry, P. \& Sclater, J.G., 1977. An analysis of the variation of ocean floor bathymetry and heat flow with age. Journal of Geophysical Research, 82(5), pp.803-827.

1655 Pasyanos, M.E., Masters, T.G., Laske, G., \& Ma, Z., 2014. LITHO1.0: An updated crust and 1656 lithospheric model of the Earth. Journal of Geophysical Research, [Solid Earth], 119(3), $1657 \quad$ pp.2153-2173.

1658 Peacock, S.M., 1993. The importance of blueschist $\rightarrow$ eclogite dehydration reactions in 1659 subducting oceanic crust. Geological Society of America bulletin, 105(5), pp.684-694.

1660 Pearce, F.D., Rondenay, S., Sachpazi, M., Charalampakis, M. \& Royden, L.H., 2012. Seismic 1661 investigation of the transition from continental to oceanic subduction along the western 
Hellenic Subduction Zone. Journal of Geophysical Research, [Solid Earth], 117(B7). Available at: http://dx.doi.org/10.1029/2011jb009023.

1664 Pearson, D.G., Carlson, R.W., Shirey, S.B., Boyd, F.R. \& Nixon, P.H.,1995. Stabilisation of 1665 Archaean lithospheric mantle: A ReOs isotope study of peridotite xenoliths from the 1666 Kaapvaal craton. Earth and Planetary Science Letters, 134(3-4), pp.341-357.

1667 Percival, J.A. \& Pysklywec, R.N., 2007. Are Archean lithospheric keels inverted? Earth and 1668 Planetary Science Letters, 254(3-4), pp.393-403.

1669 Pilia, S., Rawlinson, N., Cayley, R.A., Bodin, T., Musgrave, R., Reading, A.M., Direen, N.G., \& Young, M.K., 2015. Evidence of micro-continent entrainment during crustal accretion.

1672 Polat, A. \& Kerrich, R., 2006. Reading the geochemical fingerprints rchean hot subduction volcanic rocks: Evidence for accretion and crustal recycling in a mobile tectonic regime. In

1675 Pollack, H.N., 1986. Cratonization and thermal evolution of the mantle. Earth and Planetary 1676 Science Letters, 80(1-2), pp.175-182.

1677 Pollitz, F.F. \& Mooney, W.D., 2016. Seismic velocity structure of the crust and shallow mantle of 1678 the Central and Eastern United States by seismic surface wave imaging. Geophysical $1679 \quad$ Research Letters, 43(1), pp.118-126.

1680 Porritt, R.W., Miller, M.S., O’Driscoll, L., \& Teofilo da Costa, L., 2016. Continent-arc collision in 1681 the Banda Arc imaged by ambient noise tomography. Earth and Planetary Science Letters, $1682 \quad$ 449, pp.246-258.

1683 Porritt, R.W. Allen, R.M., Boyarko, D.C., \& Brudzinski, M.R., 2011. Investigation of Cascadia 
1684

1685

1686

1687

1688

1689

1690

1691

1692

1693

1694

1695

1696

1697

1698

1699

1700

1701

1702

1703

1704

1705 segmentation with ambient noise tomography. Earth and Planetary Science Letters, 309(12), pp.67-76.

Porritt, R.W., Allen, R.M. \& Pollitz, F.F., 2014. Seismic imaging east of the Rocky Mountains with USArray. Earth and Planetary Science Letters, 402, pp.16-25.

Porritt, R.W., Miller, M.S. \& Darbyshire, F.A., 2015. Lithospheric architecture beneath Hudson Bay. Geochemistry, Geophysics, Geosystems, 16(7), pp.2262-2275.

Poudjom Djomani, Y.H., O’Reilly, S.Y., Griffin, W.L., \& Morgan, P., 2001. The density structure of subcontinental lithosphere through time. Earth and Planetary Science Letters, 184(3-4), pp.605-621.

Rader, E., Emry, E., Schmerr, N., Frost, D., Cheng, C., Menard, J., Yu, C.-Q., and Geist, D., 2015, Characterization and Petrological Constraints of the Midlithospheric Discontinuity: Geochemistry, Geophysics, Geosystems, v. 16, p. 3484-3504, 10.1002/2015GC005943.

Rawlinson, N., Arroucau, P., Musgrave, R., Cayley, R., Young, M., \& Salmon, M., 2014. Complex continental growth along the proto-Pacific margin of East Gondwana. Geology, 42(9), pp.783-786.

Rey, P.F., Coltice, N. \& Flament, N., 2014. Spreading continents kick-started plate tectonics. Nature, 513(7518), pp.405-408.

Richter, F.M., 1985. Models for the Archean thermal regime. Earth and Planetary Science Letters, 73(2-4), pp.350-360.

Robin, C.M.I. \& Bailey, R.C., 2009. Simultaneous generation of Archean crust and subcratonic roots by vertical tectonics. Geology, 37(6), pp.523-526.

Rondenay, S, Bostock, M., Hearn, T.M., White, D.J., \& Ellis, R.M., 2000. Lithospheric assembly 
and modification of the SE Canadian Shield: Abitibi-Grenville teleseismic experiment. Journal of Geophysical Research, [Solid Earth], 105(B6), pp.13735-13754.

1708 Rondenay, S., Bostock, M., \& Fischer, K.M., 2005. Multichannel inversion of scattered 1709 teleseismic body waves: Practical considerations and applicability. In Geophysical $1710 \quad$ Monograph Series. pp. 187-203.

1711 Rondenay, S., Montési, L.G.J., \& Abers, G., 2010. New geophysical insight into the origin of the 1712 Denali volcanic gap. Geophysical Journal International, 182(2), pp.613-630.

1713 Rudnick, R.L., 1995. Making continental crust. Nature, 378(6557), pp.571-578.

1714 Rudnick, R.L., McDonough, W.F. \& O'Connell, R.J., 1998. Thermal structure, thickness and 1715 composition of continental lithosphere. Chemical Geology, 145(3-4), pp.395-411.

1716 Rychert, C.A., Rondenay, S. \& Fischer, K.M., 2007. P -to- S and S -to- P imaging of a sharp 1717 lithosphere-asthenosphere boundary beneath eastern North America. Journal of 1718 Geophysical Research, 112(B8). Available at: http://dx.doi.org/10.1029/2006jb004619.

1719 Rychert, C.A. \& Shearer, P.M., 2009. A global view of the lithosphere-asthenosphere boundary. $1720 \quad$ Science, 324(5926), pp.495-498.

1721 Sandiford, M., Van Kranendonk, M.J.,\& Bodorkos, S., 2004. Conductive incubation and the 1722 origin of dome-and-keel structure in Archean granite-greenstone terrains: A model based 1723 on the eastern Pilbara Craton, Western Australia. Tectonics, 23(1). Available at: $1724 \quad$ http://dx.doi.org/10.1029/2002tc001452.

1725 Sandu, C., Lenardic, A., O’Neill, C.J., \& Cooper, C.M., 2011. Earth's evolving stress state and 1726 the past, present, and future stability of cratonic lithosphere. International Geology Review, $1727 \quad$ 53(11-12), pp.1392-1402. 
1728 Sanns, W., 2012. Catastrophe Theory. In Mathematics of Complexity and Dynamical Systems.

$1729 \quad$ pp. 32-48.

1730 Savage, B., Brian, S. \& Silver, P.G., 2008. Evidence for a compositional boundary within the 1731 lithospheric mantle beneath the Kalahari craton from S receiver functions. Earth and 1732 Planetary Science Letters, 272(3-4), pp.600-609.

1733 Savage, M.K., 1998. Lower crustal anisotropy or dipping boundaries? Effects on receiver 1734 functions and a case study in New Zealand. Journal of Geophysical Research, [Solid 1735 Earth], 103(B7), pp.15069-15087.

1736 Saygin, E., Erdinc, S. \& Kennett, B.L.N., 2012. Crustal structure of Australia from ambient 1737 seismic noise tomography. Journal of Geophysical Research, [Solid Earth], 117(B1). 1738 Available at: http://dx.doi.org/10.1029/2011jb008403.

1739 Schaeffer, A.J. \& Lebedev, S., 2013. Global shear speed structure of the upper mantle and 1740

1741 Schmandt, B. \& Fan-Chi, L., 2014. P and S wave tomography of the mantle beneath the United 1742 States. Geophysical Research Letters, 41(18), pp.6342-6349.

1743 Schmandt, B. \& Humphreys, E., 2010. Complex subduction and small-scale convection 1744 revealed by body-wave tomography of the western United States upper mantle. Earth and $1745 \quad$ Planetary Science Letters, 297(3-4), pp.435-445.

1746 Schmandt, B. \& Humphreys, E., 2011. Seismically imaged relict slab from the 55 Ma Siletzia 1747 accretion to the northwest United States. Geology, 39(2), pp.175-178.

1748 Schulte-Pelkum, V., Vera, S.-P. \& Mahan, K.H., 2014. A method for mapping crustal 1749 deformation and anisotropy with receiver functions and first results from USArray. Earth 
and Planetary Science Letters, 402, pp.221-233.

1751 Selway, K., Heather, F. \& Peter, K., 2015. The seismic mid-lithosphere discontinuity. Earth and 1752 Planetary Science Letters, 414, pp.45-57.

1753 Shen, W., Ritzwoller, M.H. \& Schulte-Pelkum, V., 2013. A 3-D model of the crust and uppermost 1754 mantle beneath the Central and Western US by joint inversion of receiver functions and 1755 surface wave dispersion. Journal of Geophysical Research, [Solid Earth], 118(1), pp.2621756276.

1757 Shirey, S.B. \& Richardson, S.H., 2011. Start of the Wilson cycle at 3 Ga shown by diamonds 1758 from subcontinental mantle. Science, 333(6041), pp.434-436.

1759 Sigloch, K., 2011. Mantle provinces under North America from multifrequency P wave 1760 tomography. Geochemistry, Geophysics, Geosystems, 12(2). Available at: $1761 \quad$ http://dx.doi.org/10.1029/2010gc003421.

1762 Silver, P.G. \& Chan, W., 1988. Implications for continental structure and evolution from seismic 1763 anisotropy. Nature, 335(6185), pp.34-39.

1764 Sizova, E., Gerya, T. \& Brown, M., 2014. Contrasting styles of Phanerozoic and Precambrian 1765 continental collision. Gondwana Research, 25(2), pp.522-545.

1766 Sizova, E., T. V. Gerya, K. Stüwe, and M. Brown, 2015. Generation of felsic crust in the 1767 Archean: A geodynamic modeling perspective, Precambrian Research, 271, 198-224, 1768 doi:10.1016/j.precamres.2015.10.005.

1769 Sleep, N.H., 2003b, Survival of Archean cratonal lithosphere, Journal of Geophysical Research, 1770 [Solid Earth], 108(B6). Available at http://dx.doi.org/10.1029/2001JB000169.

1771 Smart, K.A., Tappe, S., Stern, R.A., Webb, S.J.,\& Ashwal, L.D., 2016. Early Archaean tectonics 

and mantle redox recorded in Witwatersrand diamonds. Nature Geoscience, 9(3), pp.255259.

1774 Steinberger, B. \& Becker, T.W., 2016. A comparison of lithospheric thickness models.

1775 Tectonophysics. Available at: http://dx.doi.org/10.1016/j.tecto.2016.08.001.

1776 Tang, M., Chen, K. \& Rudnick, R.L., 2016. Archean upper crust transition from mafic to felsic 1777 marks the onset of plate tectonics. Science, 351(6271), pp.372-375.

1778 Tapponnier, P., Le Peltzer, G., Le Dain, A.Y., \& Cobbold, P.R., 1982. Propagating extrusion 1779 tectonics in Asia: New insights from simple experiments with plasticine. Geology, 10(12), $1780 \quad$ p.611.

1781 Tetreault, J.L. \& Buiter, S.J.H., 2012. Geodynamic models of terrane accretion: Testing the fate 1782 of island arcs, oceanic plateaus, and continental fragments in subduction zones. Journal of 1783 Geophysical Research, [Solid Earth], 117(B8). Available at:

$1784 \quad$ http://dx.doi.org/10.1029/2012jb009316.

1785 Tharimena, S., Rychert, C.A., \& Harmon, N., 2016. Seismic imaging of a mid-lithospheric 1786 discontinuity beneath Ontong Java Plateau. Earth and Planetary Science Letters, 450, $1787 \quad$ pp.62-70.

1788 Thybo, H. \& Perchuc, E., 1997. The Seismic 8degrees Discontinuity and Partial Melting in 1789 Continental Mantle. Science, 275(5306), pp.1626-1629.

1790 Turcotte, D.L., 1989. A heat pipe mechanism for volcanism and tectonics on Venus. Journal of 1791 Geophysical Research, [Solid Earth], 94(B3), pp.2779-2785.

1792 Turcotte, D.L. \& Oxburgh, E.R., 1967. Finite amplitude convective cells and continental drift. $1793 \quad$ Journal of Fluid Mechanics, 28(01), p.29. 
1794 Turcotte, D.L. \& Schubert, G., 2002. Geodynamics, Cambridge University Press.

1795 van der Hilst, R. \& Paul, M., 1994. Tectonic implications of tomographic images of subducted 1796 lithosphere beneath northwestern South America. Geology, 22(5), p.451.

1797 van Hunen, J. \& Allen, M.B., 2011. Continental collision and slab break-off: A comparison of 3-D 1798 numerical models with observations. Earth and Planetary Science Letters, 302(1-2), pp.27179937.

1800 van Hunen, J. \& van den Berg, A.P., 2008. Plate tectonics on the early Earth: Limitations 1801 imposed by strength and buoyancy of subducted lithosphere. Lithos, 103(1-2), pp.217-235.

1802 van Hunen, J. \& Moyen, J.-F., 2012. Archean Subduction: Fact or Fiction? Annual Review of $1803 \quad$ Earth and Planetary Sciences, 40(1), pp.195-219.

1804 Vinnik, L.P., 1977. Detection of waves converted from P to SV in the mantle. Physics of the $1805 \quad$ Earth and Planetary Interiors, 15(1), pp.39-45.

1806 Vogt, K. \& Gerya, T.V., 2014. From oceanic plateaus to allochthonous terranes: Numerical 1807 modelling. Gondwana Research, 25(2), pp.494-508.

1808 Wagner, L.,Forsyth, D.W., Fouch, M.J., \& James, D.E., 2010. Detailed three-dimensional shear 1809 wave velocity structure of the northwestern United States from Rayleigh wave tomography. 1810 Earth and Planetary Science Letters, 299(3-4), pp.273-284.

1811 Watts, A. B., Zhong, S.J., \& Hunter, J., 2013. The Behavior of the Lithosphere on Seismic to 1812 Geologic Timescales, Annual Review of Earth and Planetary Science, 41(1), 443-468, 1813 doi:10.1146/annurev-earth-042711-105457.

1814 West, J. D., Fouch, M. J., Roth, J. B., \& Elkins-Tanton, L. T., 2009. Vertical mantle flow 1815 associated with a lithospheric drip beneath the Great Basin. Nature Geoscience, 2(6), 439- 
1817 Wilhem, C., Windley, B.F. \& Stampfli, G.M., 2012. The Altaids of Central Asia: A tectonic and 1818 evolutionary innovative review. Earth-Science Reviews, 113(3-4), pp.303-341.

1819 Wirth, E.A. \& Long, M.D., 2014. A contrast in anisotropy across mid-lithospheric discontinuities beneath the central United States--A relic of craton formation. Geology, 42(10), pp.851854.

1822 Wittlinger, G. \& Farra, V., 2007. Converted waves reveal a thick and layered tectosphere beneath the Kalahari super-craton. Earth and Planetary Science Letters, 254(3-4), pp.404415.

1825 Wood, R., 2014. Exploring the decoupling and removal of dense material during lithospheric thickening as applicable to craton formation. Master of Science in Geology. Washington State University.

1828 Wortel, M.J. \& Spakman, W., 2000. Subduction and slab detachment in the Mediterranean1829 Carpathian region. Science, 290(5498), pp.1910-1917.

1830 Worthington, L.L., Van Avendonk, H.J.A., Gulick, S.P.S., Christeson, G.L., \& Pavlis, T.L., 2012.

1831 Crustal structure of the Yakutat terrane and the evolution of subduction and collision in 1832 southern Alaska. Journal of Geophysical Research, [Solid Earth], 117(B1). Available at: 1833 http://dx.doi.org/10.1029/2011jb008493.

1834 Yang, Y., Shen, W., \& Ritzwoller, M.H., 2011. Surface wave tomography on a large-scale 1835 seismic array combining ambient noise and teleseismic earthquake data. Earthquake $1836 \quad$ Science, 24(1), pp.55-64.

1837 Yuan, H. \& Romanowicz, B., 2010. Lithospheric layering in the North American craton. Nature, 

466(7310), pp.1063-1068.

1839 Yuan, X. Kind, R., Li, X., \& Wang, R., 2006. The S receiver functions: synthetics and data 1840 example. Geophysical Journal International, 165(2), pp.555-564.

1841 Zandt, G., Gilbert, H., Owens, T. J., Ducea, M., Saleeby, J., \& Jones, C. H., 2004. Active 1842 foundering of a continental arc root beneath the southern Sierra Nevada in California. $1843 \quad$ Nature, 431(7004), 41-46.

1844 Zhu, H., Bozdag, E., \& Tromp, J., 2012. Structure of the European upper mantle revealed by 1845 adjoint tomography. Nature Geoscience, 5(7), pp.493-498. 